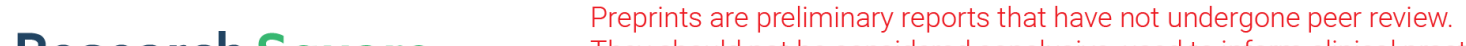 They should not be considered conclusive, used to inform clinical practice, or referenced by the media as validated information. \\ Estimation of Runoff under changed climatic scenario of a Meso Scale River by Neural Network Based Gridded Model Approach
}

Debajit Das ( $\sim$ das.debu1995.12@gmail.com )

National Institute of Technology Agartala https://orcid.org/0000-0001-5751-2558

Tilottama Chakraborty

National Institute of Technology Agartala

Mrinmoy Majumder

National Institute of Technology Agartala

Tarun Kanti Bandyopadhyay

National Institute of Technology Agartala

\section{Research Article}

Keywords: Climate change, GMDH model, Rainfall-runoff, general circulation models, HadGEM2-ES, Gomati River Basin

Posted Date: March 12th, 2021

DOl: https://doi.org/10.21203/rs.3.rs-223790/v1

License: (9) This work is licensed under a Creative Commons Attribution 4.0 International License. Read Full License 


\title{
Estimation of Runoff under changed climatic scenario of a Meso Scale River by Neural Network Based Gridded Model Approach
}

\author{
Debajit Das ${ }^{1}$, Tilottama Chakraborty ${ }^{2}$, Mrinmoy Majumder ${ }^{3}$ \\ and Tarun Kanti Bandyopadhyay ${ }^{4}$
}
${ }^{1}$ M. Tech scholar NIT, Agartala, (Hydro-Informatics Engineering) Jirania 799046, India
${ }^{2,3}$ Assistant Professor NIT, Agartala, (Hydro-Informatics Engineering) Jirania 799046, India
${ }^{4}$ Assistant Professor NIT, Agartala, (Chemical Engineering) Jirania 799046, India
${ }^{1}$ E-mail address: das.debu1995.12@gmail.com
${ }^{2}$ E-mail address: tilottama86@gmail.com
${ }^{3}$ E-mail address: mmajumder15@gmail.com
${ }^{4}$ E-mail address: tarunkantibanerjee0@gmail.com

\begin{abstract}
As climate change is linked with changes in precipitation, evapotranspiration and changes in other climatological parameters, these changes will be affected runoff of a river basin. Gomati River basin is the largest river basin among all the river basin of Tripura. Due to the increase in settlement in the Gomati river basin and climate change may threaten natural flow patterns that endure its diversity. This study assesses the impact of climate change on total flow of a catchment in North East India (Gomati River catchment). For this assessment, the Group Method of Data Handling Modeling System (GMDH) model was used to simulate the rainfallrunoff relationship of the catchment, with respect to the observed data during the period of 2008-2009. The statistically downscaled outputs of HadGEM2-ES (Hadley Centre Global Environment Model version 2), general circulation models (GCMs) scenario was used to assess the impacts of climate change on the Gomati River Basin. Future projections were developed
\end{abstract}


for the 2030s, 2040s and 2050s projections, respectively. The results from the present study can contribute to the development of adaptive strategies and future policies for the sustainable management of water resources in North East, Tripura.

Keywords: Climate change, GMDH model, Rainfall-runoff, general circulation models, HadGEM2-ES, and Gomati River Basin.

\section{$1 \quad$ Introduction}

The climate is likely to change due to the increase in green-house effect. This will further affect the changes in temperature distribution in time and space. Since 1920s, the temperature of planet Earth has shown an increasing trend. In the recent period number of warm years have already exceeded the expected range of natural variability (Hadley Centre 1997). The expected rise in mean surface temperature is $0.3-0.6^{\circ} \mathrm{C}$ per decade in the current century (IPCC 2001). Also India's average temperature rose by around $0.7^{\circ} \mathrm{C}$ between 1901 and 2018 . It is projected to rise further by approximately $4.4^{\circ} \mathrm{C}$ by the end of this century (Assessment of Climate Change over the Indian Region, 2020). Key hydrological processes in water cycle like precipitation directly depends on this change in temperature. It has been also seen that the areas over Central India, the South-West coast, the Southern peninsula and North-East India have experienced two droughts per decades on average in the last few decades (Assessment of Climate Change over the Indian Region, 2020). This results in change in the spatio-temporal variation of water resources in a river basin (Kundzewicz et al., 2007). Therefore, river discharges are likely to change in volume and distribution over the year. Quantitative information on these changes required to set the long term policies for future river management.

Thus the projection of river discharge is needed to deal with water-related disasters made by climate change, such as floods, droughts, and water scarcity etc. On this point, Hydrologic and flow routing models play a key part in converting the climate model outputs into river discharge. It is possible to evaluate future changes in water resources availability, flood 
discharge, droughts, etc., and especially possible future hotspots on water related disasters can be identified only by using projections of river discharge information. 1-degree spatial resolution runoff model with general circulation model (GCM) outputs has been used to study the variations in the future threats of floods and droughts on a global scale (Hirabayashi et al., 2008 and Pokhret et al., 2010). While the 1-degree spatial resolution runoff model is enough for analyzing river discharge variations on a global scale, it is not suitable for analyzing variations at the regional or country scale. In contrast, detailed, high-resolution hydrological models have been used to study the impact of climate change at the basin scale (Kim et al. 2009; Kim et al., 2010; Kiem et al., 2008). It is hard to use such type of high resolution complex hydrological models to identify the hotspots in the regional or country scale because of the high computational charges related to hydrological models and complications in finding model parameters.

These above studies shows that, due to the climate change the change in temperature, precipitation, evapotranspiration and changes in other climatological parameters takes place. Therefore it becomes necessary to know the change in flow patterns and the availability of water resource for that region as it directly depends on the all climatological parameters of that region.

\subsection{Objective of the Study}

i. To conduct rainfall-runoff simulation of Gomati river basin.

ii. Application of gridded approach on the behaviour of hydrological system of Gomati river basin.

iii. To assess the impact of climate change on Rainfall-Runoff relationship. 


\subsection{Study area}

Tripura is a tiny state of North-East India with a geographical area of $10,486 \mathrm{~km}^{2}$ (Source: THE MASTER PLAN OF GUMTI SUB-BASIN, 1996) which is bordered by Bangladesh on three sides. The Gomati river basin is located in the lower middle part of Tripura spreading from eastern to western boundary of the state. The catchment area of river Gomati is $2205.04 \mathrm{~km}^{2}$ within the boundary of Indian and also it has the largest basin among all the rivers of Tripura. The catchment area is nearly $21.03 \%$ of the total geographic area of Tripura. Most of the population of this state is directly or indirectly dependent on this river on daily basis. So it is the most important river of Tripura. Gomati River basin is the largest river basin of Tripura. The basin area resides within three districts i.e. Gomati, Dhalai and Sepahijala which has a large chunk of population of the state. The Gomati River basin also has the largest water resource availability among all the river basins of Tripura. It also has the one and only hydro power project Tripura at Dumboor. So the importance of this river basin is by far the most among all the river basin of this state. But in recent years due to the influence of climate change it has been seen that the water resource availability of this basin changing drastically which is affecting the life of residents of this basin directly or indirectly. It has been also seen that change in water resource availability reduces the output of the hydel power project at Dumboor. Therefore it is very important to know the impact of climate change on the water resource availability of Gomati River basin. This is the sole purpose of conducting this study in Gomati River basin. 


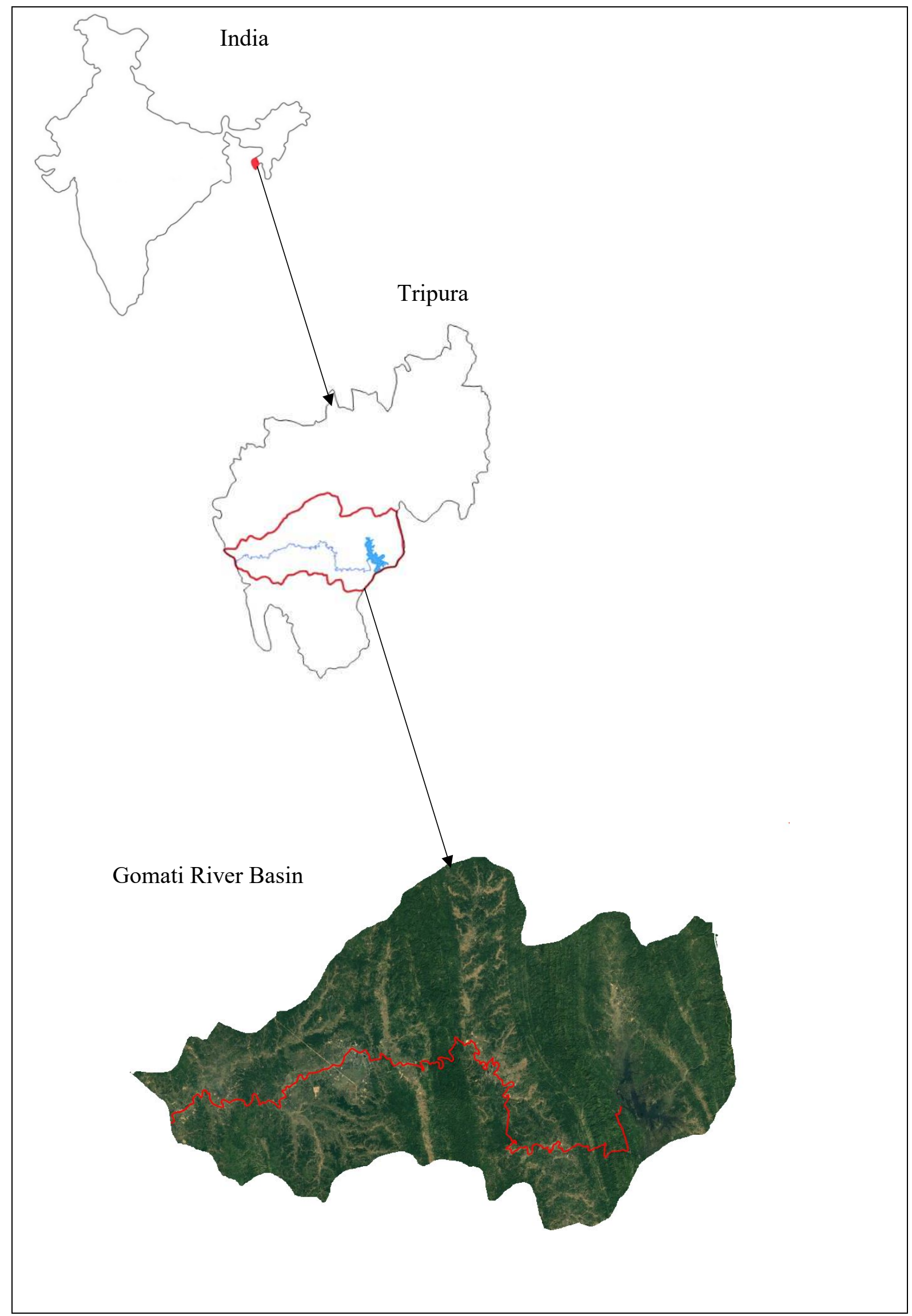

Fig. 1. Study Area (Gomati River Basin)

(Source: https://thumbs.dreamstime.com/b/print-173735639.jpg) 
Objective: To study the impact of climate change on rainfall-runoff relationship of Gomati River Basin

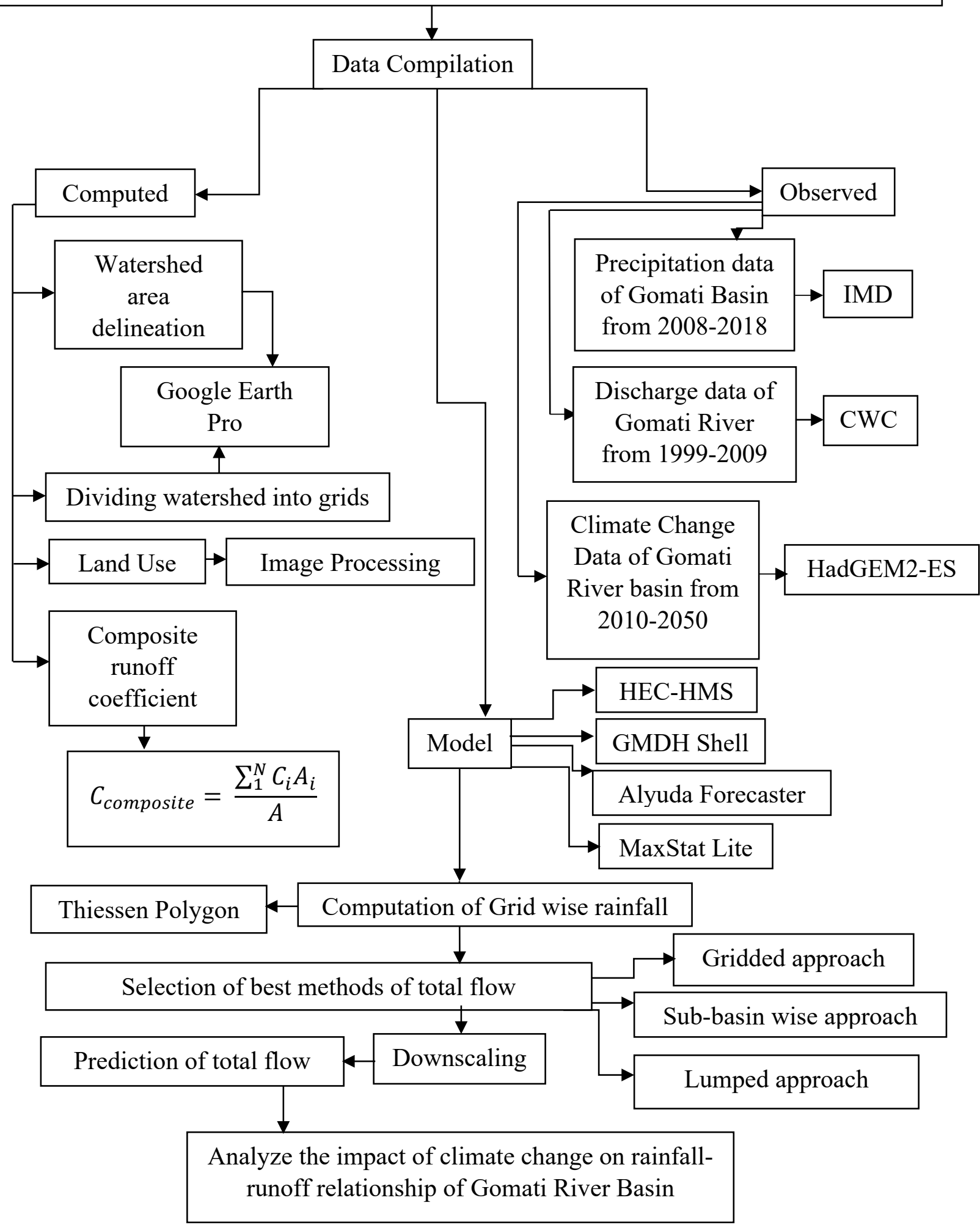

Figure 2: Flow chart showing the methodology of the present study objective 


\subsection{Data Compilation}

In the present study various data have been compiled for the development of model. The catchment boundary and watershed area of Gomati River Basin has been delineated using Google Earth Pro (calculated in section 3.1) and divided into 19 grids of $15 \mathrm{~km} \times 15 \mathrm{~km}$ size. Land use land cover data (calculated in section 3.2) is extracted by Geomatica FreeView software using Google earth imagery of Gomati river basin. Then composite runoff coefficient (calculated in section 3.3) is computed by taking runoff coefficient for agricultural land, settlement and forest land as 0.28, 0.45 and 0.35 (Subramanya, K. Engineering Hydrology, 4e. Tata McGraw-Hill Education, 2013). The equation used for computing composite runoff coefficient (Subramanya, K. Engineering Hydrology, 4e. Tata McGraw-Hill Education, 2013) is shown in equation no. 1 .

$$
C_{\text {Composite }}=\frac{\sum_{1}^{N} C_{i} A_{i}}{A}
$$

Precipitation data of Gomati basin (2008-2018) has been collected from India Meteorological Department (IMD).

Discharge data of Gomati River (1999-2009) has been collected from Central Water Commission (CWC). In the present study, the base flow value was considered by observing the secondary data collected from CWC.

Climate change data of Gomati basin (2010-2050) has been compiled using HadGEM2-ES climate model for scenario RCP-2.60 (Source: http://gismap.ciat.cgiar.org/MarkSimGCM/).

The station wise observed rainfall data of 2008-2018 (collected from IMD) were converted into grid wise rainfall data (calculated in section 3.6) using Thiessen polygon method (Subramanya, K. Engineering Hydrology, 4e. Tata McGraw-Hill Education, 2013).

The present study involves the application of different approaches of computation of total runoff in the form of gridded approach, station wise approach and lumped approach using D8 
method (calculated in section 3.7). After the computation of total runoff through these different approaches, the best approach is determined and base flow of the river is added to the runoff which gives the total flow.

Grid wise downscaled GCM data of 2010 to 2018 has been compared with the grid wise observed rainfall data (i.e. computed using Thiessen polygon) and grid wise absolute error has been computed (calculated in section 3.8). Finally the weighted average of grid wise absolute error has been computed.

The prediction of total flow (calculated in section 3.10) for the Gomati River Basin has been done by using the best approach for total flow computation which has been found earlier in the study.

\subsection{Modeling Techniques}

In the current study eight modeling techniques has been compared to compute the runoff for the study basin. The modeling techniques which has been used in the current study are HEC-HMS (Charley et al., 1995), GMDH (Ivakhnenko et al., 1995), Quick propagation (Brust et al., 2016), Conjugate gradient descent (Stiefel et al., 1952, Levenberg-Marquardt (Marquardt et al., 1963) Incremental back propagation (Fu et al., 1996), Batch back propagation (Al Duais et al. 2016) and Multiple linear regression (Freedman et al., 2009) etc. A climate model (i.e. HadGEM2-ES (Collins et al., 2011)) has been also used in this study to analyze the impact of climate change in rainfall-runoff.

\subsection{Error Measurement of the Model}

After developing this models using random values, accuracy has been analyzed with the help of root mean square error (RMSE), correlation (R), coefficient of determination $\left(\mathrm{R}^{2}\right)$, mean absolute error (MAE), NES and PBIAS (Source: D. N. Moriasi et al., 2007). 
The satisfactory and unsatisfactory range of errors for root mean square error (RMSE), correlation (R), coefficient of determination $\left(\mathrm{R}^{2}\right)$, mean absolute error (MAE), NES and PBIAS has been shown in table 1 .

Table 1: Range of errors [D. N. Moriasi et al., 2007]

\begin{tabular}{|l|l|l|}
\hline Root mean square error & Satisfactory & Unsatisfactory \\
(RMSE) & $0 \leq \mathrm{RMSE} \leq 0.5$ & RMSE $>0.5$ \\
\hline Coefficient of determination & $1 \geq$ Correlation $\leq-1$ & $1<$ Correlation $>-1$ \\
\hline $\left.\mathbf{R}^{2}\right)$ & & $1 \geq$ Correlation $\leq-1$ \\
\hline Correlation & MAE $<0.5$ of Standard & MAE $\geq 0.5$ of Standard \\
\hline Mean absolute error (MAE) & Deviation & Deviation \\
\hline NES & $0.5<$ NES $\leq 1$ & NES $\leq 0.5$ \\
\hline PBIAS & $\pm 0.1<$ PBIAS $\leq \pm 0.25$ & PBIAS $> \pm 0.25$ \\
\hline
\end{tabular}

\subsection{Downscaling}

Climate change data has been acquired from the climate model HadGEM2-ES using climate scenario as RCP 2.6 for 19 grids for the period of 2010 to 2050 . But this type of GCM data are in of coarse scales, so this data need to be converted in local scales. In the present, study delta method of statistical downscaling approach is used to downscale the climate data. The equation used for delta method of statistical downscaling (Dessu and Melesse, 2013) is shown in equation no. 8 . 


$$
P_{S D}^{\text {Delta }}=P_{G C M r c p} \times \frac{\bar{P}_{\text {Obs }}}{\bar{P}_{G C M h i s t .}}
$$

Where, $P_{S D}^{\text {Delta }}$ is the downscaled data of precipitation, $\bar{P}_{\text {Obs }}$ refers the average observed

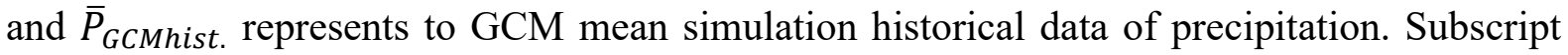
GCMrcp represents the GCM's RCP outputs over the future period and subscript Obs represents the observation values.

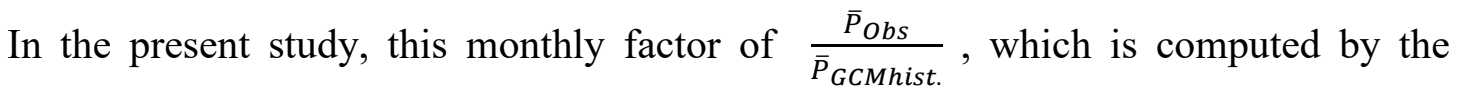
downscaling of GCM data (i.e. 2010-2018) is used to downscale future GCM data (i.e. 20212050).

\subsection{Climate change scenario}

For evaluating the future climate change impact on the flow of Gomati River basin future climate data (i.e. precipitation) has been acquired from a climate model HadGEM2-ES. It is one of the most reliable climate models of recent times. By using this model, climate data of 2030s, 2040s and 2050s (given in section 3.9) is acquired which is used in GMDH model.

\section{$3 \quad$ Results and discussion}

\subsection{Watershed Area Delineation}

Figure No. 3 depicts the area of Gomati River basin, which is delineated with the help of Google Earth Pro software by joining the highest elevation points around the Gomati River. After delineation of watershed with the help of polygon tool in same software the area of watershed is computed which is found to be $2205.04 \mathrm{~km}^{2}$. 


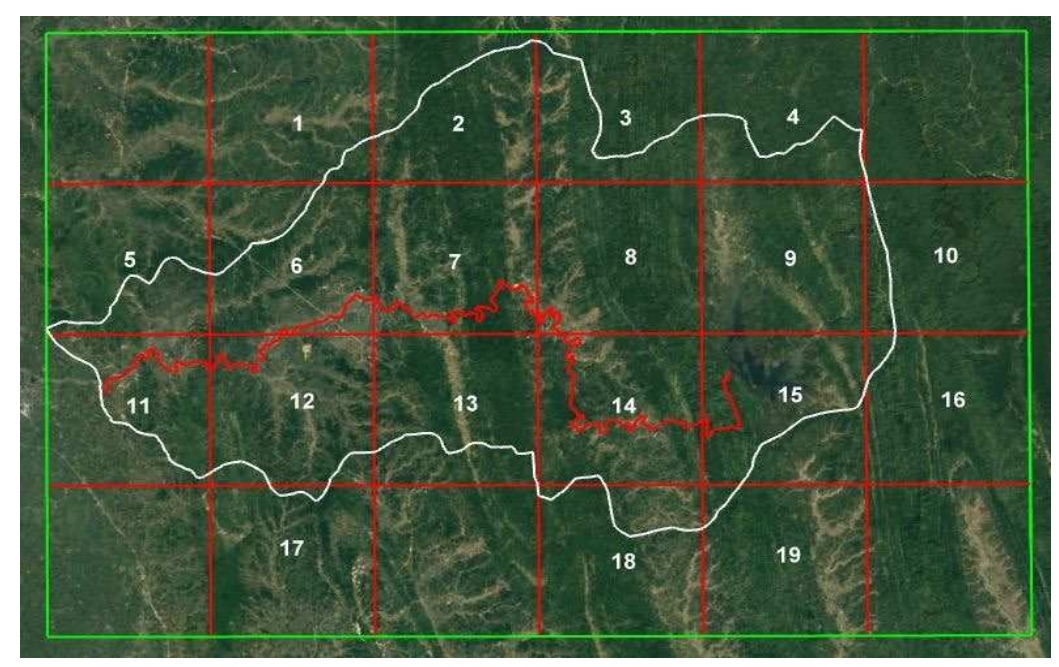

Figure 3: Gomati River Basin area with 19 grids of 15 km $\times 15$ km size

\subsection{Image Processing}

After the delineation of watershed it is divided into 19 grids of $15 \mathrm{~km} \times 15 \mathrm{~km}$ using Google Earth Pro. Snaps of all the 19 grids are taken and land use data of each grid is computed with the help of Geomatica FreeView software. Table 2 shows the grid wise land use data of Gomati River basin.

Table 2: Grid wise land use data of Gomati River Basin

\begin{tabular}{|c|c|c|c|c|c|c|}
\hline $\begin{array}{c}\text { Grid } \\
\text { Number }\end{array}$ & $\operatorname{Area}\left(\mathrm{km}^{2}\right)$ & $\begin{array}{l}\% \text { area of } \\
\text { settlement }\end{array}$ & $\begin{array}{c}\% \text { area } \\
\text { of } \\
\text { forest }\end{array}$ & $\begin{array}{c}\% \text { area of } \\
\text { water } \\
\text { body }\end{array}$ & $\begin{array}{c}\% \text { area of } \\
\text { agricultural } \\
\text { land }\end{array}$ & $\begin{array}{c}\% \text { area } \\
\text { of barren } \\
\text { land }\end{array}$ \\
\hline 1 & 12.80 & 0.00 & 70.23 & 0.00 & 29.54 & 0.24 \\
\hline 2 & 151 & 0.00 & 82.82 & 0.00 & 14.76 & 2.41 \\
\hline 3 & 104 & 0.00 & 55.35 & 0.00 & 43.51 & 1.14 \\
\hline 4 & 72.20 & 0.00 & 57.06 & 0.00 & 42.41 & 0.53 \\
\hline 5 & 61.90 & 0.00 & 40.71 & 0.00 & 57.61 & 1.67 \\
\hline 6 & 168 & 2.34 & 62.59 & 4.82 & 30.17 & 0.83 \\
\hline 7 & 225 & 3.26 & 69.92 & 2.00 & 24.55 & 0.26 \\
\hline
\end{tabular}




\begin{tabular}{|c|c|c|c|c|c|c|}
\hline 8 & 225 & 0.00 & 57.77 & 0.50 & 39.59 & 2.14 \\
\hline 9 & 225 & 1.56 & 72.41 & 11.73 & 14.26 & 0.04 \\
\hline 10 & 25.70 & 0.00 & 98.17 & 1.83 & 0.00 & 0.001 \\
\hline 11 & 118 & 2.01 & 53.32 & 5.36 & 38.15 & 1.16 \\
\hline 12 & 205 & 3.18 & 17.35 & 0.17 & 79.30 & 0.00 \\
\hline 13 & 166 & 2.02 & 77.3 & 0.18 & 18.83 & 1.24 \\
\hline 14 & 224 & 1.14 & 70.51 & 0.66 & 26.60 & 1.09 \\
\hline 15 & 159 & 1.06 & 62.57 & 35.84 & 0.00 & 0.53 \\
\hline 16 & 8.31 & 0.00 & 98.05 & 0.00 & 1.68 & 0.27 \\
\hline 17 & 4.46 & 0.00 & 96.12 & 1.12 & 2.69 & 0.07 \\
\hline 18 & 41.67 & 2.73 & 69.84 & 0.00 & 23.55 & 3.88 \\
\hline 19 & 8.00 & 0.19 & 95.06 & 0.00 & 1.75 & 3.00 \\
\hline Total & 2205.04 & 1.47 & 62.22 & 4.82 & 30.54 & 0.99 \\
& & & & & & \\
\hline
\end{tabular}

The highest percentage of settlement is found at grid no. 7 due to fact that it has the largest and most populated city (i.e. Udaipur) of Gomati River Basin. Grid no. 15 also has the highest percentage of water body because most part of Dumboor Lake belongs to this grid.

\subsection{Grid Wise Runoff Coefficient}

The composite runoff coefficient is computed by taking runoff coefficient for agricultural land, settlement and forest land as $0.28,0.45$ and 0.35 . The grid wise runoff coefficient and composite runoff coefficient of total watershed is shown in table 3. 
Table 3: Grid wise runoff coefficient

\begin{tabular}{|c|c|c|c|c|c|c|}
\hline $\begin{array}{l}\text { Grid } \\
\text { No }\end{array}$ & Area $\left(\mathrm{km}^{2}\right)$ & $\begin{array}{l}\% \text { area of } \\
\text { settlement }\end{array}$ & $\begin{array}{c}\% \text { area } \\
\text { of } \\
\text { forest }\end{array}$ & $\begin{array}{c}\% \text { area of } \\
\text { agricultural } \\
\text { land }\end{array}$ & $\begin{array}{c}\% \text { area of } \\
\text { barren } \\
\text { land }\end{array}$ & $\begin{array}{c}\text { Runoff } \\
\text { coefficient } \\
\text { (C) }\end{array}$ \\
\hline 1 & 12.8 & 0.00 & 70.23 & 29.54 & 0.24 & 0.346 \\
\hline 2 & 151 & 0.00 & 82.82 & 14.76 & 2.41 & 0.355 \\
\hline 3 & 104 & 0.00 & 55.35 & 43.51 & 1.14 & 0.335 \\
\hline 4 & 72.2 & 0.00 & 57.06 & 42.41 & 0.53 & 0.336 \\
\hline 5 & 61.9 & 0.00 & 40.71 & 57.61 & 1.67 & 0.324 \\
\hline 6 & 168 & 2.34 & 62.59 & 30.17 & 0.83 & 0.332 \\
\hline 7 & 225 & 3.26 & 69.92 & 24.55 & 0.26 & 0.345 \\
\hline 8 & 225 & 0 & 57.77 & 39.59 & 2.14 & 0.335 \\
\hline 9 & 225 & 1.56 & 72.41 & 14.26 & 0.04 & 0.316 \\
\hline 10 & 25.7 & 0.00 & 98.17 & 0.00 & 0.001 & 0.361 \\
\hline 11 & 118 & 2.01 & 53.32 & 38.15 & 1.163 & 0.321 \\
\hline 12 & 205 & 3.18 & 17.35 & 79.3 & 0.00 & 0.312 \\
\hline 13 & 166 & 2.02 & 77.3 & 18.83 & 1.24 & 0.353 \\
\hline 14 & 224 & 1.14 & 70.51 & 26.6 & 1.09 & 0.346 \\
\hline 15 & 159 & 1.06 & 62.57 & 0.00 & 0.532 & 0.237 \\
\hline 16 & 8.31 & 0.00 & 98.05 & 1.68 & 0.27 & 0.366 \\
\hline 17 & 4.46 & 0.00 & 96.12 & 2.69 & 0.07 & 0.361 \\
\hline 18 & 41.67 & 2.73 & 69.84 & 23.55 & 3.88 & 0.350 \\
\hline 19 & 8.00 & 0.19 & 95.06 & 1.75 & 3.00 & 0.364 \\
\hline Total & 2205.04 & 1.47 & 62.22 & 30.54 & 0.99 & 0.328 \\
\hline
\end{tabular}




\subsection{Model Development}

For the purpose of this study mainly four types of models has been developed i.e.

- Hydrological Model (HEC-HMS)

- Polynomial Neural Network (GMDH)

- Artificial Neural Network (Quick Propagation, Conjugate Gradient Descent, Levenberg-Marquardt, Incremental Back Propagation and Batch back propagation)

- Statistical Model ( Multi Linear Regression)

After developing this models accuracy has been analyzed with the help of root mean square error (RMSE), correlation $(\mathrm{R})$, coefficient of determination $\left(\mathrm{R}^{2}\right)$, mean absolute error (MAE), NES and PBIAS. Values of the model accuracy for a given dataset is shown in table 4.

Table 4: Model accuracy for a given dataset.

\begin{tabular}{|c|c|c|c|c|c|c|c|c|c|c|c|c|c|}
\hline & & 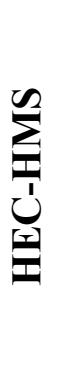 & $\sum_{0}^{\mathbb{2}}$ & 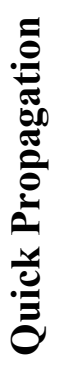 & 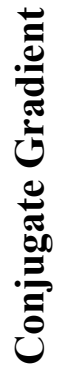 & 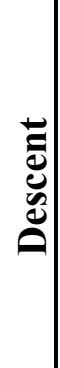 & 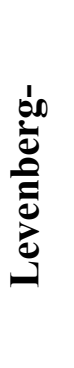 & 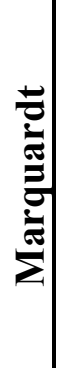 & 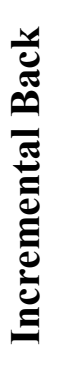 & 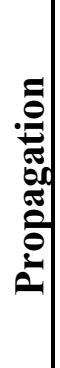 & 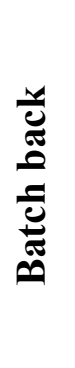 & 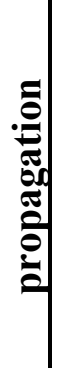 & $\frac{\underline{z}}{\xi}$ \\
\hline 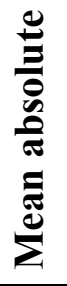 & 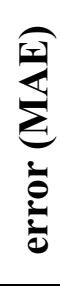 & 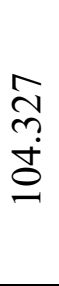 & $\begin{array}{l}\frac{n}{0} \\
0 \\
x \\
0 \\
0 \\
\text { m. }\end{array}$ & $\begin{array}{l}\circ \\
\stackrel{8}{\circ} \\
\circ\end{array}$ & $\begin{array}{l}n \\
\&\end{array}$ & & $\begin{array}{l}\text { లో } \\
0 \\
0\end{array}$ & & $\begin{array}{l}\infty \\
8 \\
\varnothing\end{array}$ & & 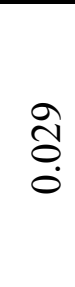 & & $\begin{array}{l}\stackrel{ \pm}{0} \\
\stackrel{0}{0}\end{array}$ \\
\hline 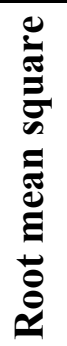 & 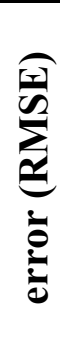 & $\frac{n}{\approx}$ & $\begin{array}{l}n \\
b \\
0 \\
x \\
8 \\
0 \\
n \\
n\end{array}$ & $\begin{array}{l}\overline{8} \\
\end{array}$ & $\stackrel{8}{\circ}$ & & $\begin{array}{l}\text { ㅇ } \\
8 \\
\stackrel{0}{0}\end{array}$ & & $\begin{array}{l}\overline{8} \\
0 \\
0\end{array}$ & & $\begin{array}{l}\text { ㅇ } \\
8 \\
0\end{array}$ & & $\begin{array}{l}\frac{a}{0} \\
\stackrel{0}{0}\end{array}$ \\
\hline
\end{tabular}




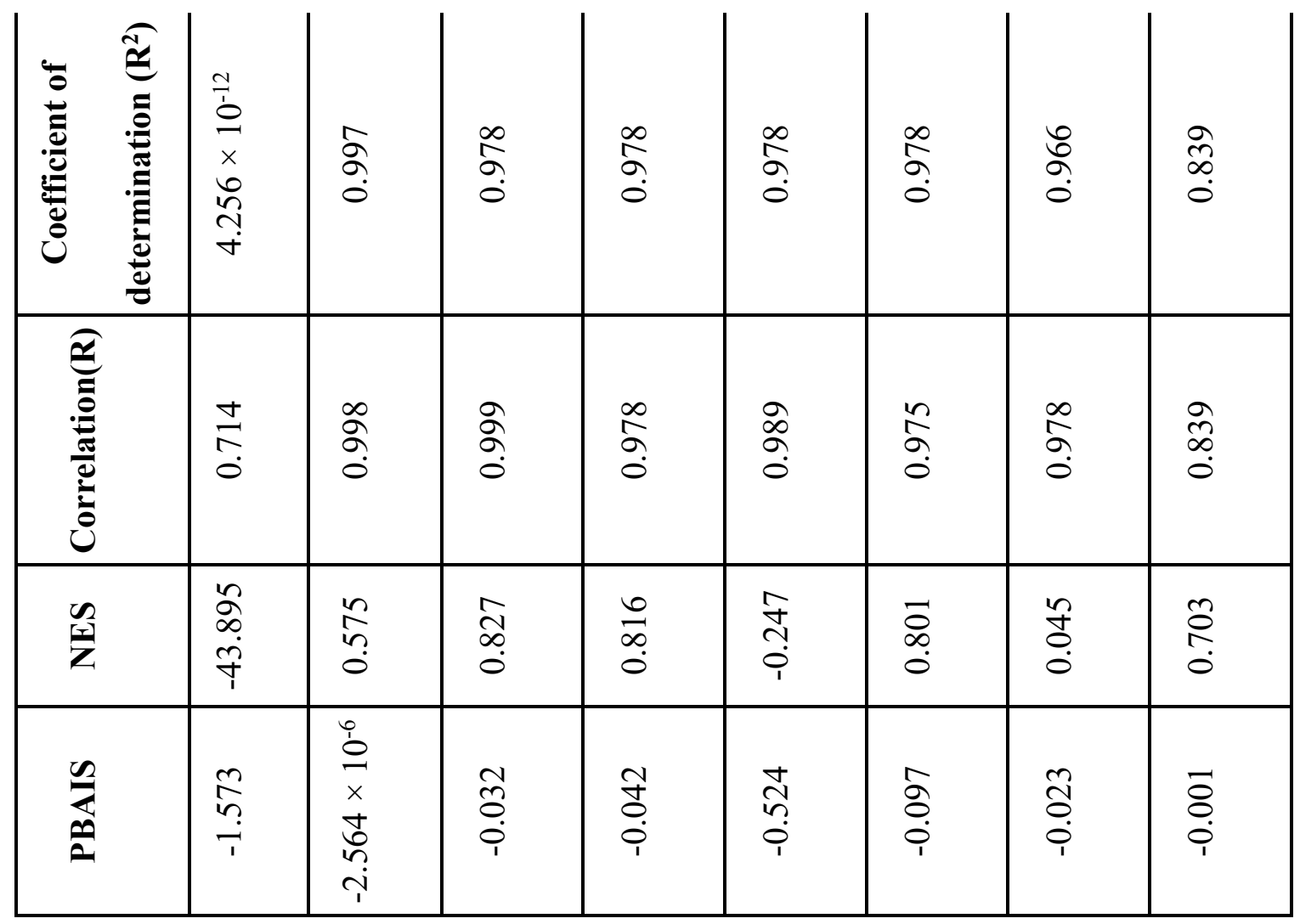

After the analysis it has been found that GMDH model has the most suitable among all these models.

A GMDH model has been developed considering the runoff coefficient, rainfall intensity and area as inputs and the runoff as output. The GMDH model has been exported into a spreadsheet for the prediction of grid wise normalized runoff of Gomati River basin. The equations of this GMDH model depicts in equation no. 9.

$\mathrm{Y} 1=-6.59439 \mathrm{e}-15+\mathrm{C}^{*} 0.00877631+\mathrm{C}^{*} \mathrm{~N} 78^{*} 1.9487+\mathrm{C}^{\wedge} 2^{*} 1.76264 \mathrm{e}-14+\mathrm{N} 78^{*} 8.09751 \mathrm{e}-$ 14

$\mathrm{N} 78=5.96635 \mathrm{e}-16+\mathrm{N} 77 * 1, \mathrm{~N} 77=-0.00450369+\mathrm{i} * \mathrm{~A} * 0.513164$

The comparison between actual and predicted values are shown in the figure no. 4 . 


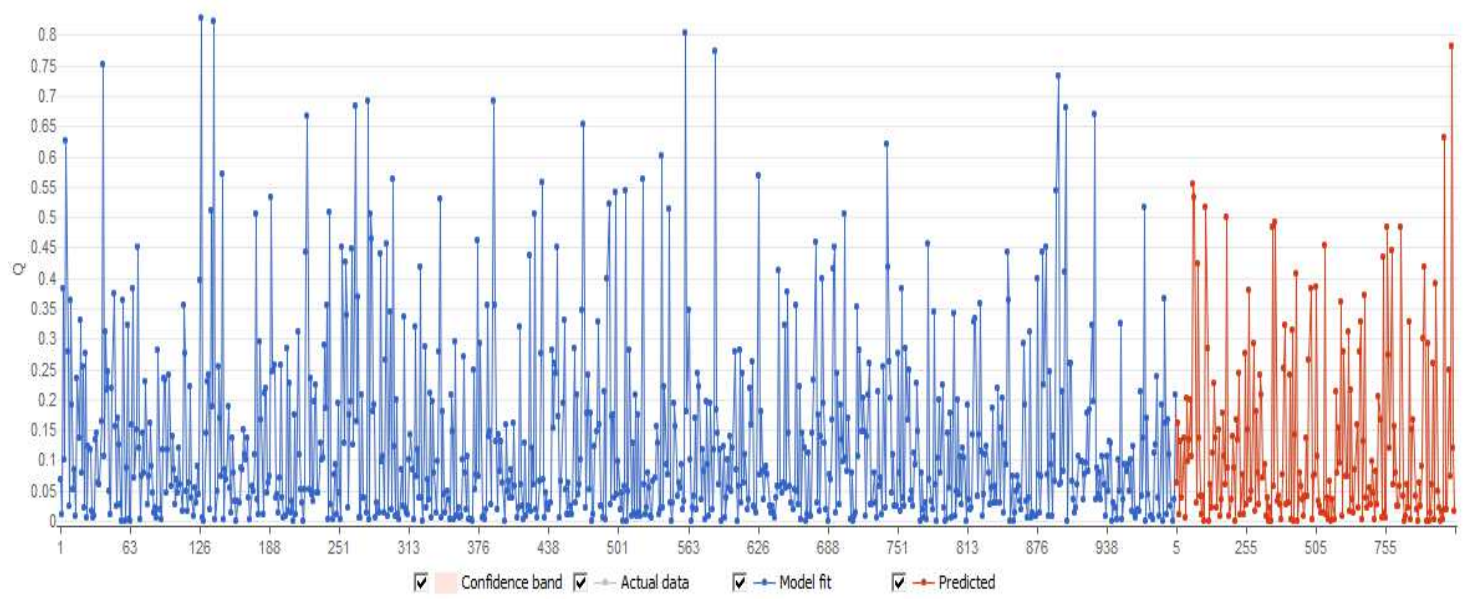

Figure 4: Showing the comparison for actual and predicted values of output

\subsection{Observed Rainfall Data}

Rainfall data of eleven years (i.e. 2008-2018) for the rain gauge stations inside the Gomati Basin (i.e. Gandecherra, Sonamura, Udaipur and Amarpur) and also outside the Gomati Basin (i.e. Teliamura, Jirania, Bishalgarh, Belonia and Bogafa) has been collected from IMD. This observed data is shown in figure 5 .

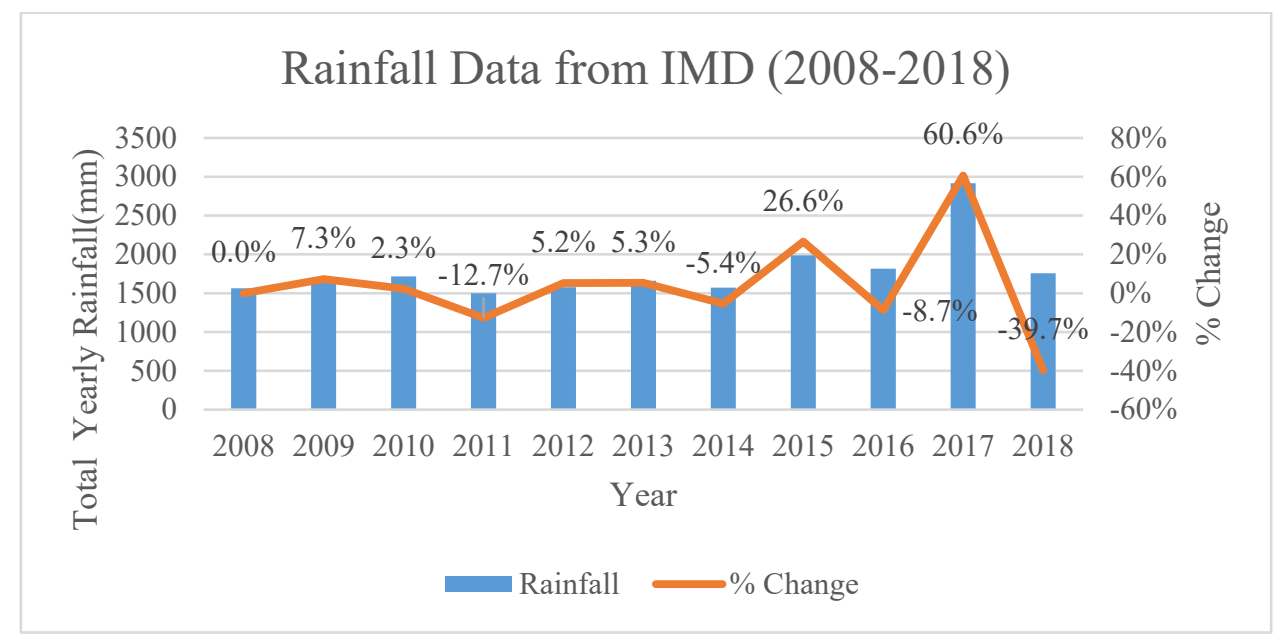

Figure 5: Graphical representation of average observed rainfall data. 


\subsection{Thiessen Polygon Method}

Station wise yearly rainfall data of IMD (2008 to 2018) has been converted into grid wise yearly rainfall data using Thiessen polygon method. An isohyetal map has been drawn on surfer with the help of grid wise rainfall data which is shown in figure 6 .

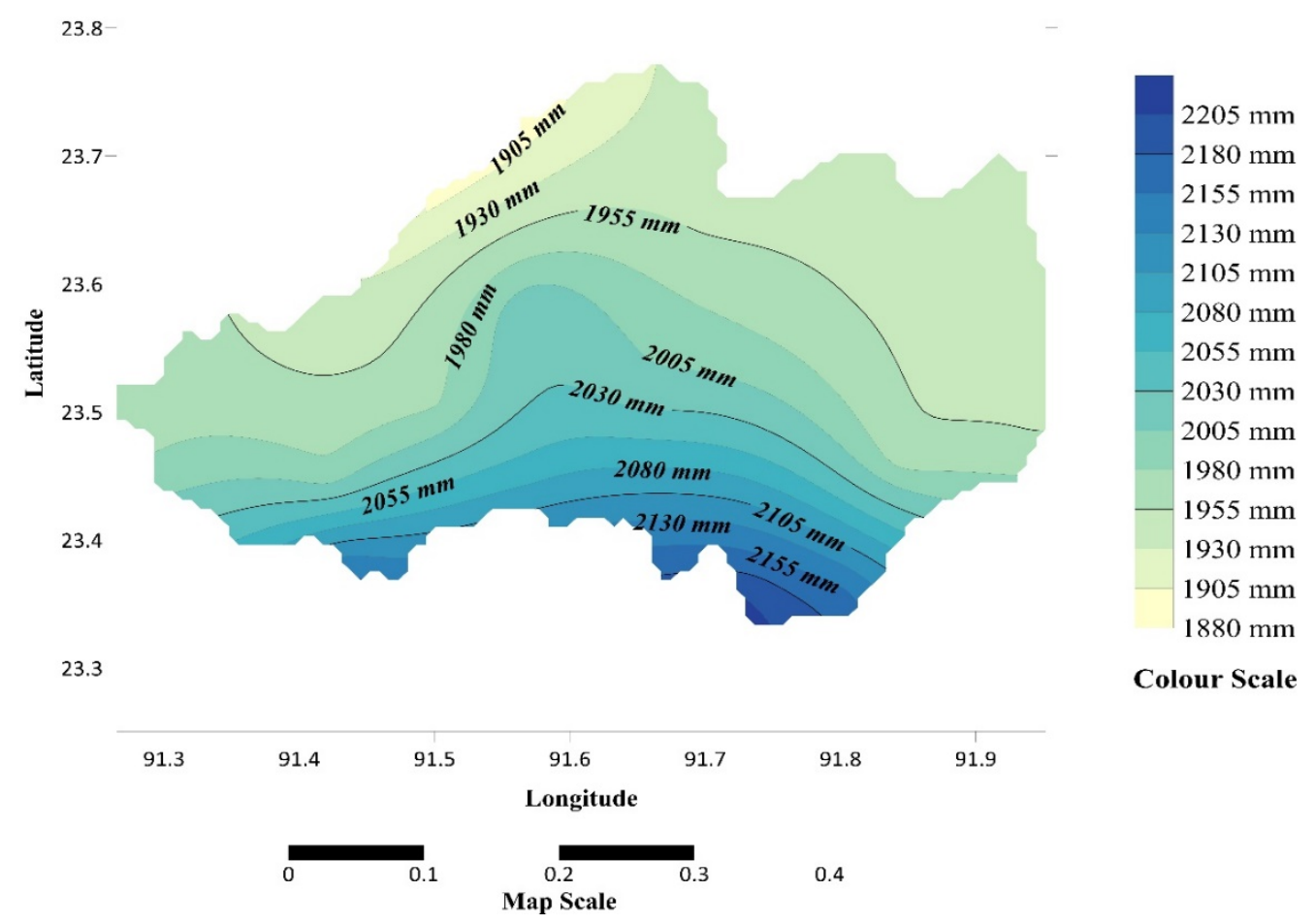

Figure 6: Graphical representation of isohyetal map of Gomati River Basin using computed grid wise average yearly rainfall data of 2008-2018

(Surfer 3D

Modelling)

\subsection{Computation of Discharge (from 2008-2009) and Selection of Best Approach}

In the present study, the base flow value was added to the surface runoff by observing the secondary data collected from CWC. The values of base flow are given in the following table 5 . 
Table 5: Yearly total base flow in cumec

\begin{tabular}{|c|c|c|c|c|}
\hline Year & 2008 & 2009 & 2008 & 2009 \\
\hline Month & \multicolumn{2}{|c|}{$\begin{array}{c}\text { Daily base flow } \\
\text { in cumec }\end{array}$} & \multicolumn{2}{c|}{$\begin{array}{c}\text { Monthly total base } \\
\text { flow in cumec }\end{array}$} \\
\hline Jan & 11 & 6 & 341 & 186 \\
\hline Feb & 11 & 6 & 308 & 168 \\
\hline Mar & 11 & 6 & 341 & 186 \\
\hline Apr & 12 & 7 & 360 & 210 \\
\hline May & 12 & 7 & 372 & 217 \\
\hline Jun & 13 & 8 & 390 & 240 \\
\hline Jul & 13 & 8 & 403 & 248 \\
\hline Aug & 13 & 8 & 403 & 248 \\
\hline Sep & 13 & 8 & 390 & 240 \\
\hline Oct & 12 & 7 & 372 & 217 \\
\hline Nov & 11 & 6 & 330 & 180 \\
\hline Dec & 11 & 6 & 341 & 186 \\
\hline Total & & & 4351 & 2526 \\
\hline & & & & \\
\hline
\end{tabular}

In the present study total flow has been computed with the help of three different approaches gridded approach, sub-basin approach and lumped approach.

\subsubsection{Gridded Approach}

After calculating grid wise total flow for the year 2008 and 2009, the total flow of Gomati River Basin has been computed with the help of D8 method. Error computation of 
computed total flow has been done with the help of observed total flow of 2008 and 2009 from Central Water Commission (CWC) which is shown in figure 7.

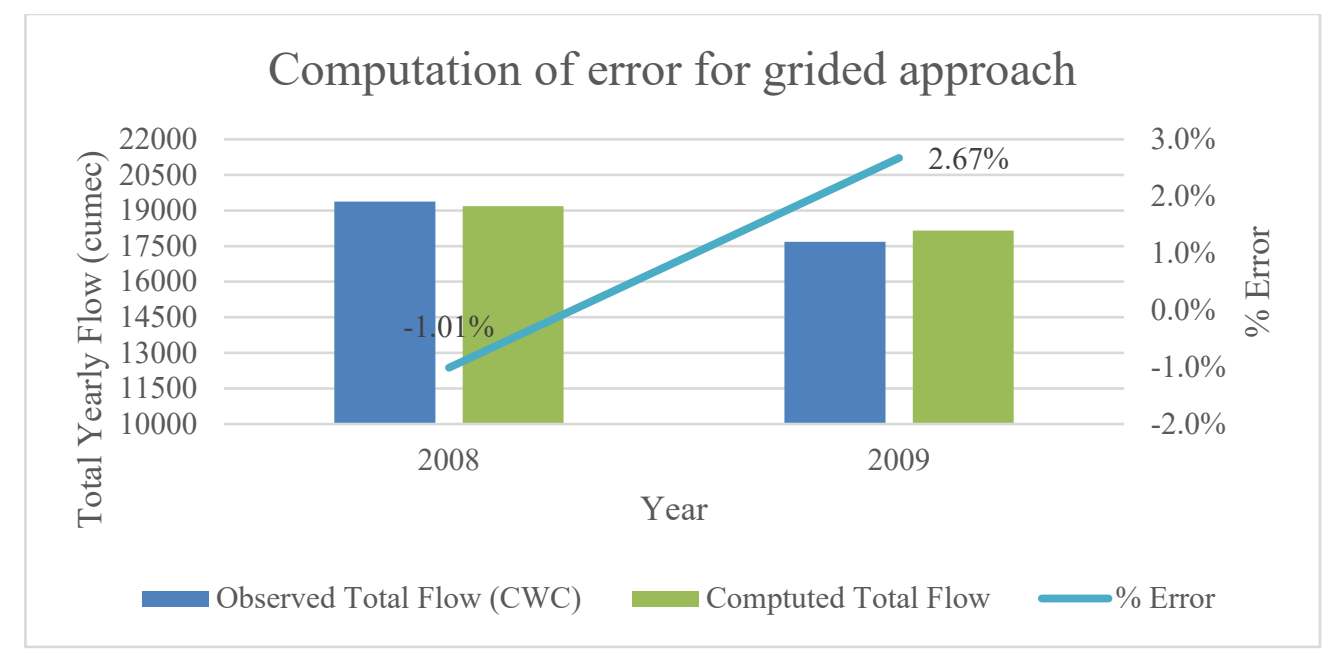

Figure 7: Graphical representation of observed total flow (CWC), computed total flow (gridded approach) and \% error.

The average yearly absolute error for the gridded approach has been found as $1.84 \%$.

\subsubsection{Sub-Basin Approach}

After calculating station wise total flow for the year 2008 and 2009, the total flow of Gomati River Basin has been computed with the help of D8 method. Error computation of computed total flow has been done with the help of observed total flow of 2008 and 2009 from Central Water Commission (CWC) which is shown in figure 8.

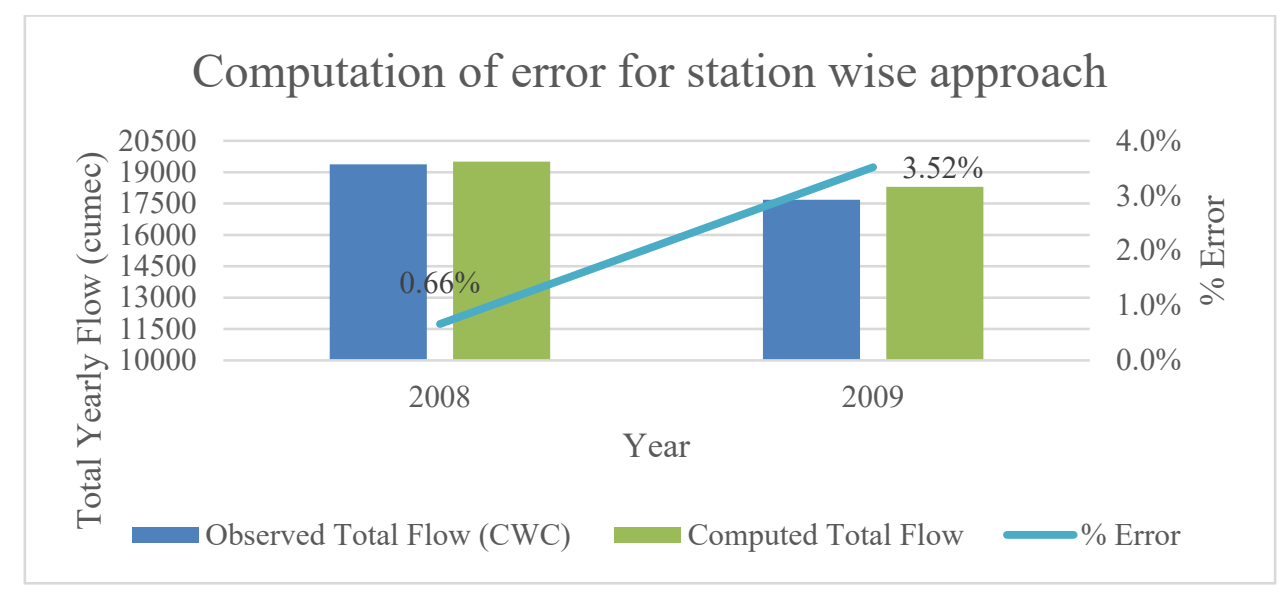


Figure 8: Graphical representation of observed total flow (CWC), computed total flow (sub-basin approach) and \% error.

The average yearly absolute error for the sub-basin approach has been found as $2.09 \%$.

\subsubsection{Lumped Approach}

After calculating total flow for the year 2008 and 2009. Error computation of computed total flow has been done with the help of observed total flow of 2008 and 2009 from Central Water Commission (CWC) which is shown in figure 9.

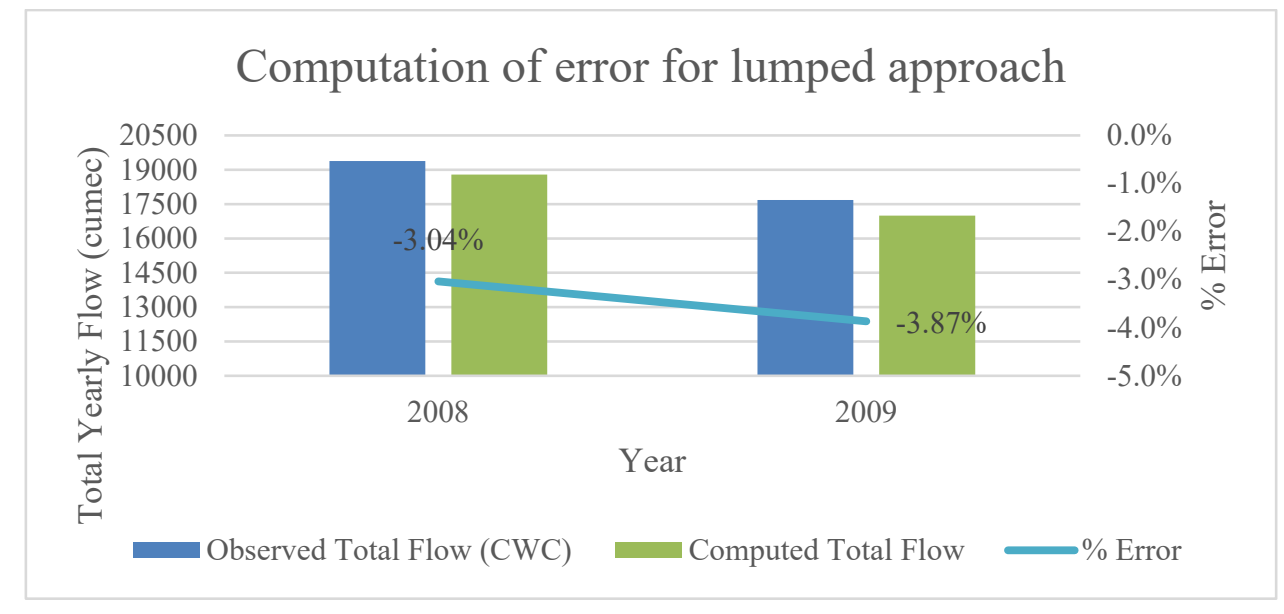

Figure 9: Graphical representation of observed total flow (CWC), computed total flow (lumped approach) and \% error.

The average yearly absolute error for the lumped approach has been found as $3.46 \%$.

After comparing all these three approach it has been found that gridded approach is the best approach for the computation of total flow of Gomati River Basin, as the approach has the lowest percentage of error compare to other approaches. 
Climate change data has been collected from the climate model HadGEM2-ES using climate scenario as RCP 2.6 for 19 grids for the period of 2010 to 2050 . But it has been seen that the GCM data has a huge variation with respect to observed data (2010-2018) from IMD (which has been converted into grid wise rainfall data with the help of Thiessen polygon). The variation has been shown in figure 10 .

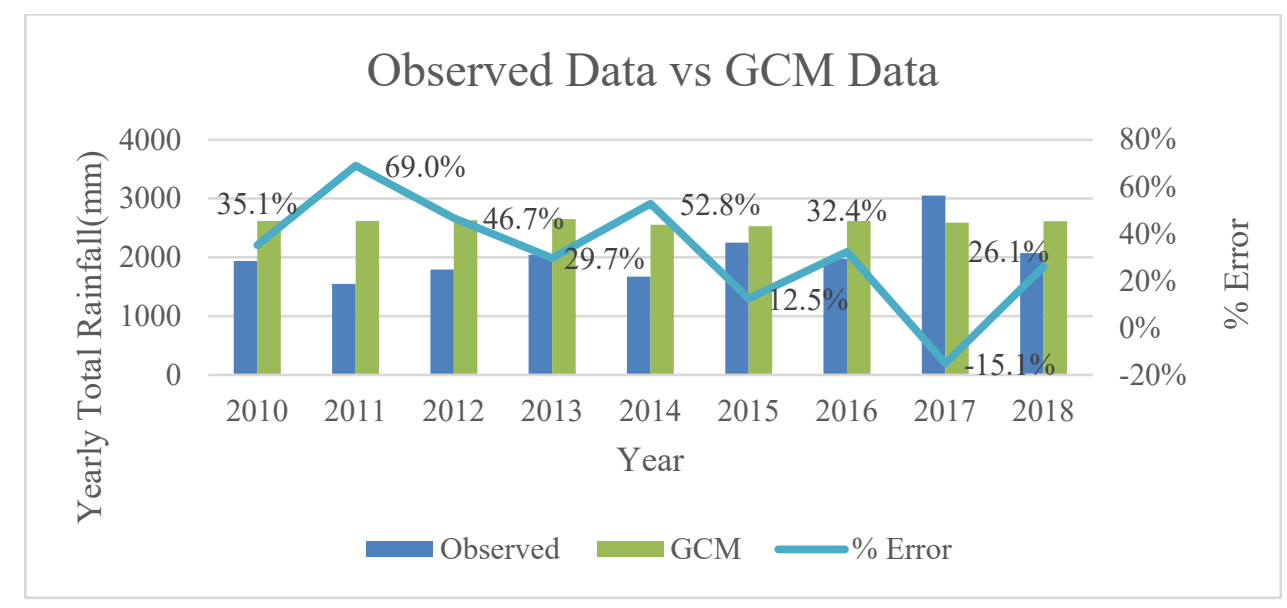

Figure 10: Graphical representation of variation in GCM data (2010-2018) with respect to observed data (2010-2018).

The average yearly absolute error has been found as $35.47 \%$, which is much higher than $20 \%$. The GCM data has been downscaled so that the average yearly absolute error can be minimized reasonably. The values of the factors which has been used to downscale the GCM data has shown in the table 6. 


\begin{tabular}{|c|c|c|c|c|c|c|c|c|c|c|c|c|}
\hline 12 & 11 & 10 & 9 & 8 & 7 & 6 & 5 & 4 & 3 & 2 & 1 & Grid no \\
\hline 0.276 & 0.201 & 0.255 & 0.205 & 0.235 & 0.133 & 0.157 & 0.107 & 0.21 & 0.233 & 0.23 & 0.211 & Jan \\
\hline 1.122 & 1.228 & 1.548 & 1.529 & 0.536 & 0.979 & 1.009 & 1.593 & 2.045 & 1.934 & 2.521 & 1.453 & Feb \\
\hline 0.869 & 0.649 & 0.604 & 1.736 & 1.278 & 3.184 & 3.401 & 2.164 & 1.101 & 1.411 & 2.419 & 3.388 & Mar \\
\hline 0.714 & 0.735 & 1.795 & 2.002 & 0.738 & 1.67 & 0.699 & 0.73 & 3.513 & 2.277 & 1.587 & 1.378 & Apr \\
\hline 0.723 & 0.704 & 0.961 & 0.91 & 0.687 & 0.769 & 0.81 & 0.754 & 0.937 & 0.884 & 0.947 & 0.745 & May \\
\hline 0.453 & 0.445 & 0.593 & 0.525 & 0.544 & 0.495 & 0.448 & 0.455 & 0.469 & 0.496 & 0.484 & 0.466 & June \\
\hline 0.575 & 0.596 & 0.503 & 0.538 & 0.527 & 0.588 & 0.584 & 0.574 & 0.514 & 0.493 & 0.459 & 0.561 & July \\
\hline 1.117 & 0.814 & 1.181 & 1.165 & 1.295 & 1.455 & 1.477 & 0.983 & 1.268 & 1.297 & 1.405 & 1.293 & Aug \\
\hline 8.798 & 10.1 & 2.108 & 1.18 & 2.638 & 2.871 & 2.413 & 9.208 & 1.24 & 1.168 & 1.058 & 2.511 & Sept \\
\hline 0.52 & 0.432 & 0.534 & 0.659 & 0.698 & 0.613 & 0.658 & 0.442 & 0.567 & 0.603 & 0.641 & 0.543 & Oct \\
\hline 0.856 & 0.941 & 0.12 & 0.219 & 0.477 & 0.819 & 0.832 & 0.911 & 0.184 & 0.485 & 0.878 & 0.711 & Nov \\
\hline 0 & 0 & 0 & 0 & 0 & 0 & 0 & 0 & 0 & 0 & 0 & 0 & Dec \\
\hline
\end{tabular}




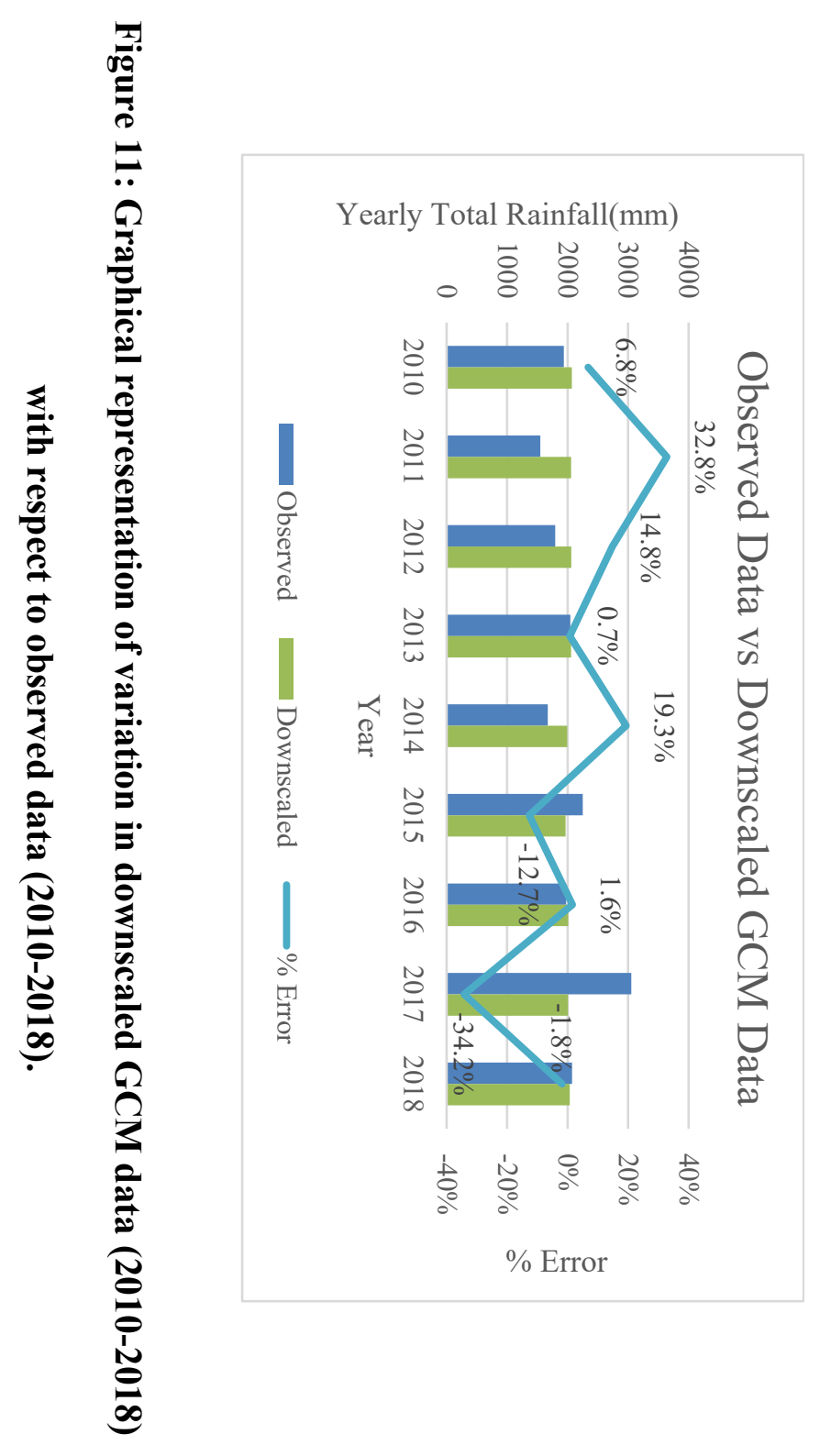

\begin{tabular}{|c|c|c|c|c|c|c|c|}
\hline \multirow[b]{2}{*}{$\vec{\sigma}$} & 19 & 18 & 17 & 16 & 15 & 14 & 13 \\
\hline & 0.077 & 0.086 & 0.101 & 0.153 & 0.198 & 0.089 & 0.098 \\
\hline . & 2.83 & 3.229 & 1.984 & 1.957 & 1.646 & 0.85 & 0.914 \\
\hline$\stackrel{\circ}{\circ}$ & 1.563 & 2.041 & 2.117 & 0.952 & 2.044 & 4.087 & 1.947 \\
\hline 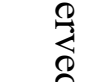 & 2.89 & 2.864 & 2.025 & 1.73 & 2.107 & 1.501 & 1.829 \\
\hline 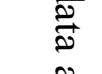 & 0.969 & 0.711 & 0.727 & 0.987 & 0.856 & 0.876 & 0.97 \\
\hline 8 & 0.519 & 0.628 & 0.524 & 0.509 & 0.561 & 0.493 & 0.626 \\
\hline 岕 & 0.624 & 0.677 & 0.707 & 0.506 & 0.52 & 0.554 & 0.633 \\
\hline$\frac{2}{3}$ & 1.43 & 1.424 & 1.498 & 1.286 & 1.143 & 1.328 & 1.4 \\
\hline 2 & 2.94 & 2.652 & 2.47 & 1.702 & 1.929 & 10.91 & 4.311 \\
\hline 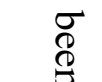 & 1.049 & 1.12 & 1.165 & 0.449 & 0.485 & 0.551 & 0.727 \\
\hline 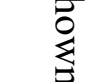 & 0.632 & 0.988 & 0.469 & 0.171 & 0.175 & 0.576 & 0.876 \\
\hline 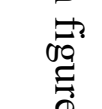 & 0 & 0 & 0 & 0 & 0 & 0 & 0 \\
\hline
\end{tabular}


After applying delta method of statistical downscaling the average yearly absolute error has been found as $13.86 \%$, which less than $20 \%$.

An isohyetal map has been drawn using this downscaled GCM data which gas been shown in figure 12.

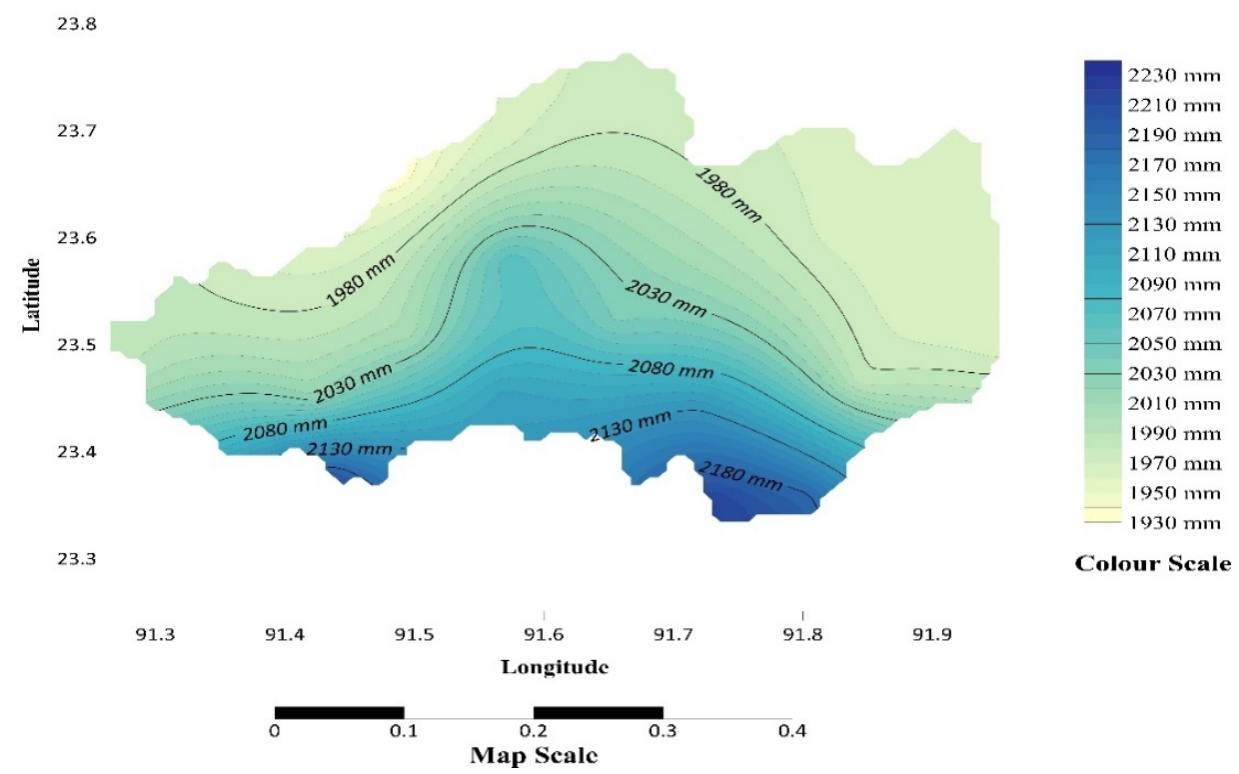

Figure 12: Graphical representation of isohyetal map of Gomati River Basin using downscaled grid wise average yearly rainfall data of 2010-2018 (Surfer 3D Modelling).

\subsection{GCM Data (2021-2050)}

For the prediction of runoff (i.e. 2030s, 2040s and 2050s) in Gomati Basin GCM data of 2021-2050 has been collected using HadGEM2-ES climate model. The collected GCM data has been graphically shown in figure 13 (2021-2030), figure 14 (2031-2040) and figure 15 (2041-2050). 

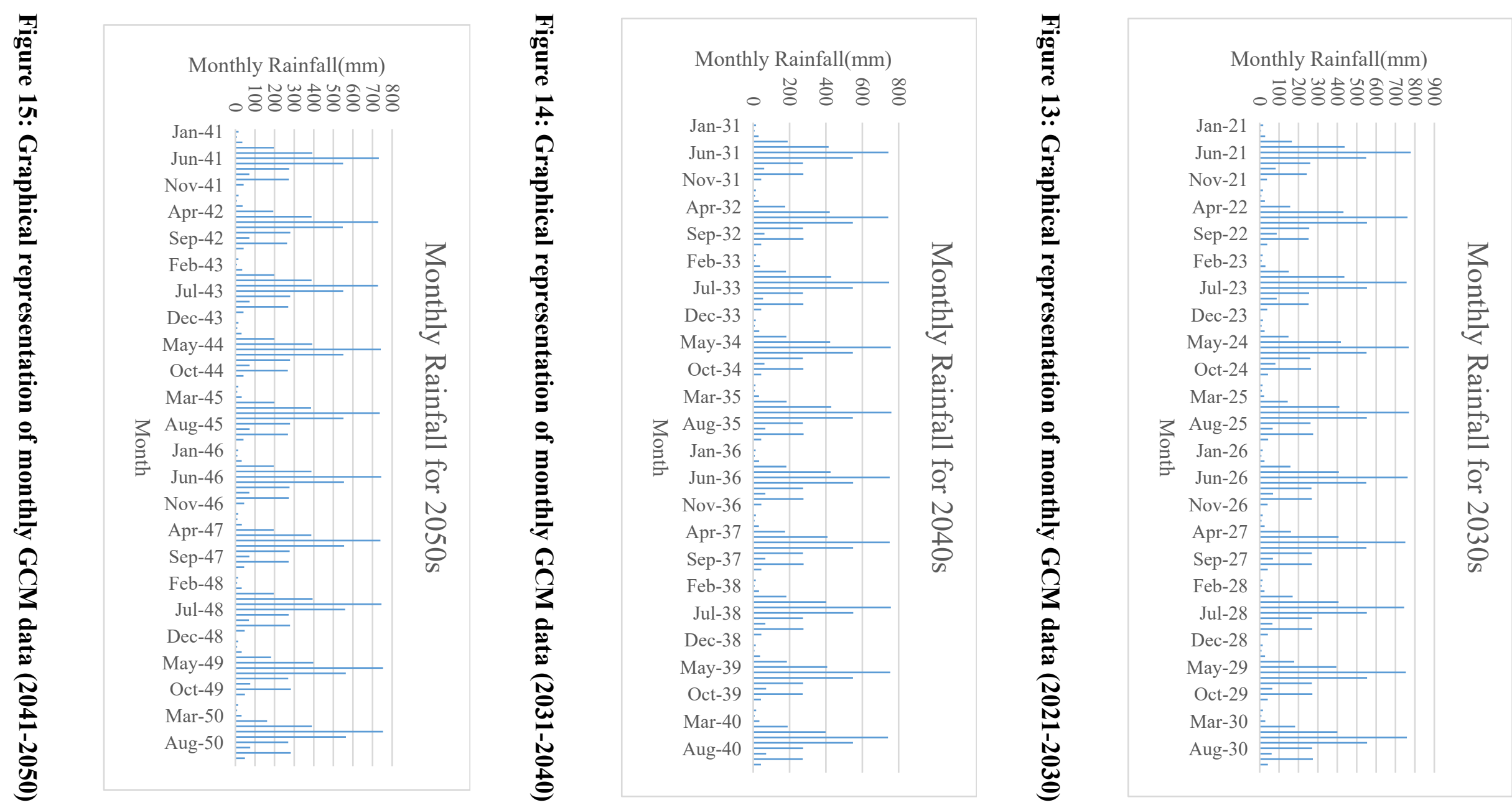
2040s and 2050s

This monthly factor of $\frac{\bar{P}_{\text {Obs }}}{\bar{P}_{\text {GCMhist. }}}$, by which the downscaling of GCM data (i.e. 20102018) has been done has also been used for the downscaling of future GCM data (i.e. 20212050). Isohyetal maps has been draw using average yearly data of 2021-30, 2031-2040 and 2041-2050 which is graphically shown in figure 16, figure 19 and figure 22.

3.10.1 Downscaled GCM Data and Total Flow of 2030s

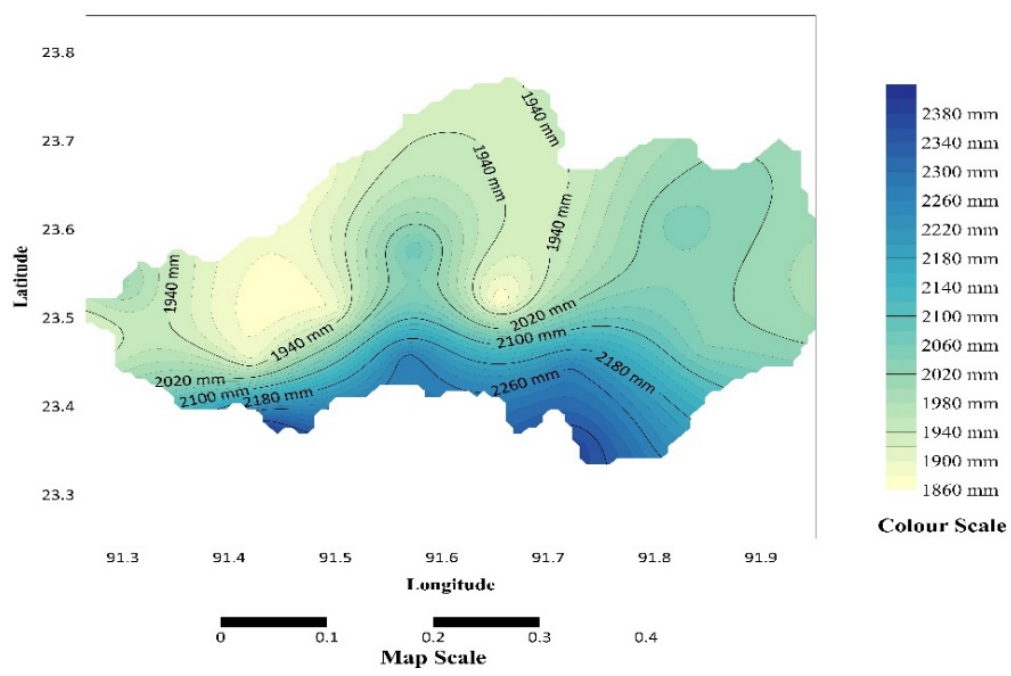

Figure 16: Graphical representation of isohyetal map of Gomati River Basin using downscaled grid wise average yearly rainfall data of 2021-2030 (Surfer 3D Modelling).

For the prediction of total flow of 2030s the best approach of total flow computation i.e. gridded approach is used. The average monthly flow and downscaled GCM data of whole Gomati Basin for 2021-2030 has been shown in figure 17. 


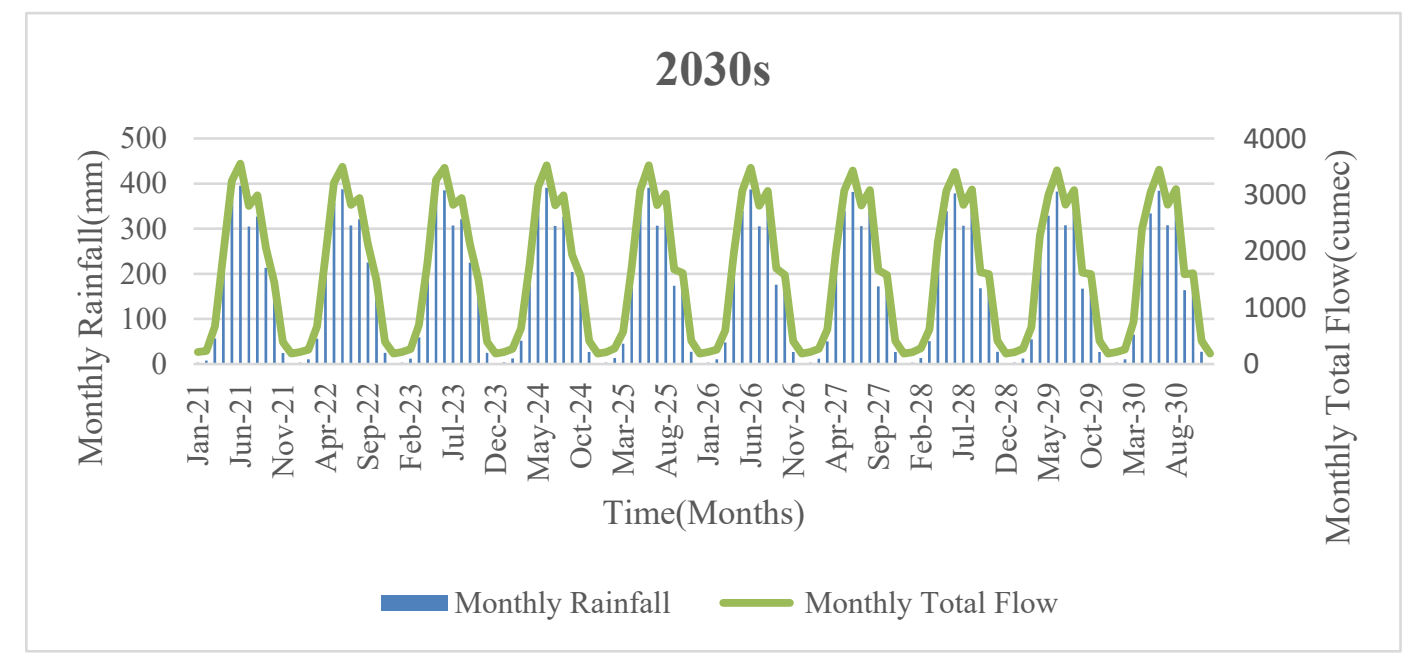

Figure 17: Graphical representation of monthly downscaled GCM data

(2021-2030)

and total flow for $2030 \mathrm{~s}$

The average yearly flow of whole Gomati Basin for 2030s has been shown in figure 18 .

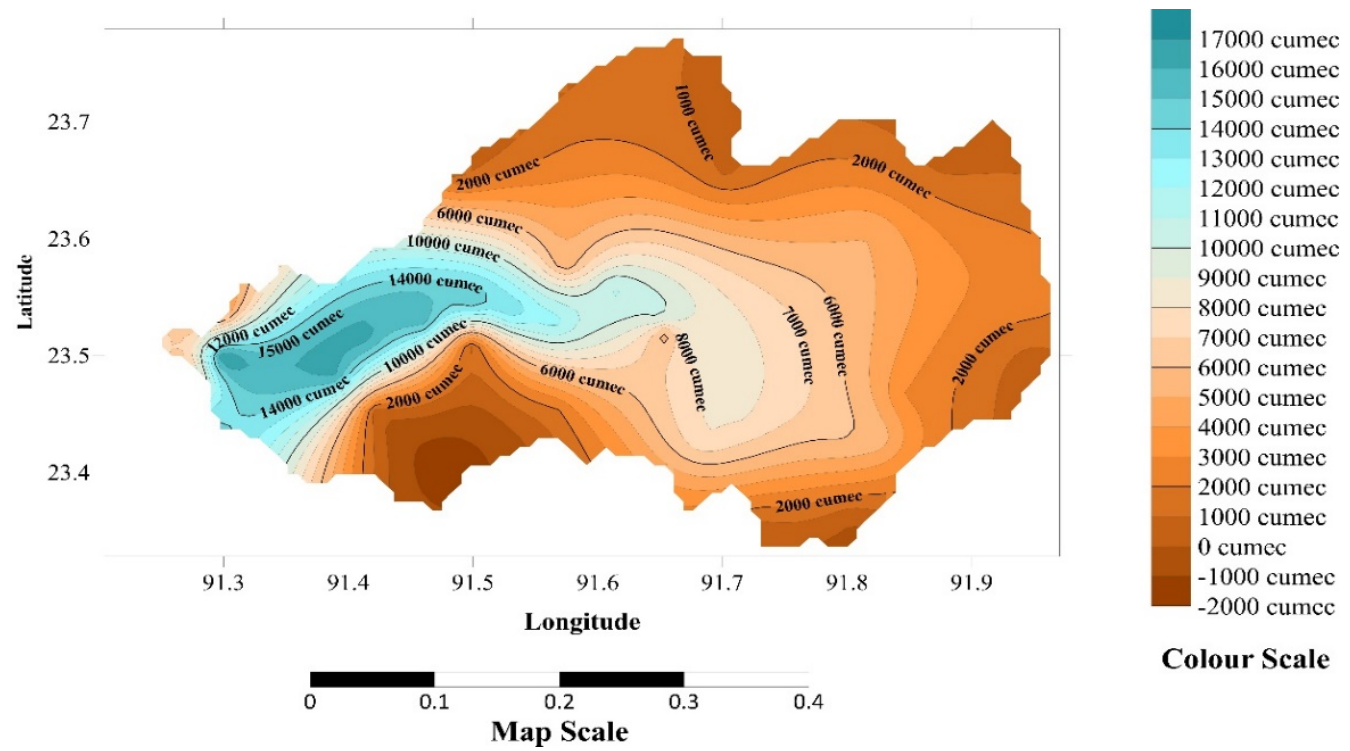

Figure 18: Graphical representation of the contour map of the total flow for 2030s on Gomati River Basin (Surfer 3D Modelling). 


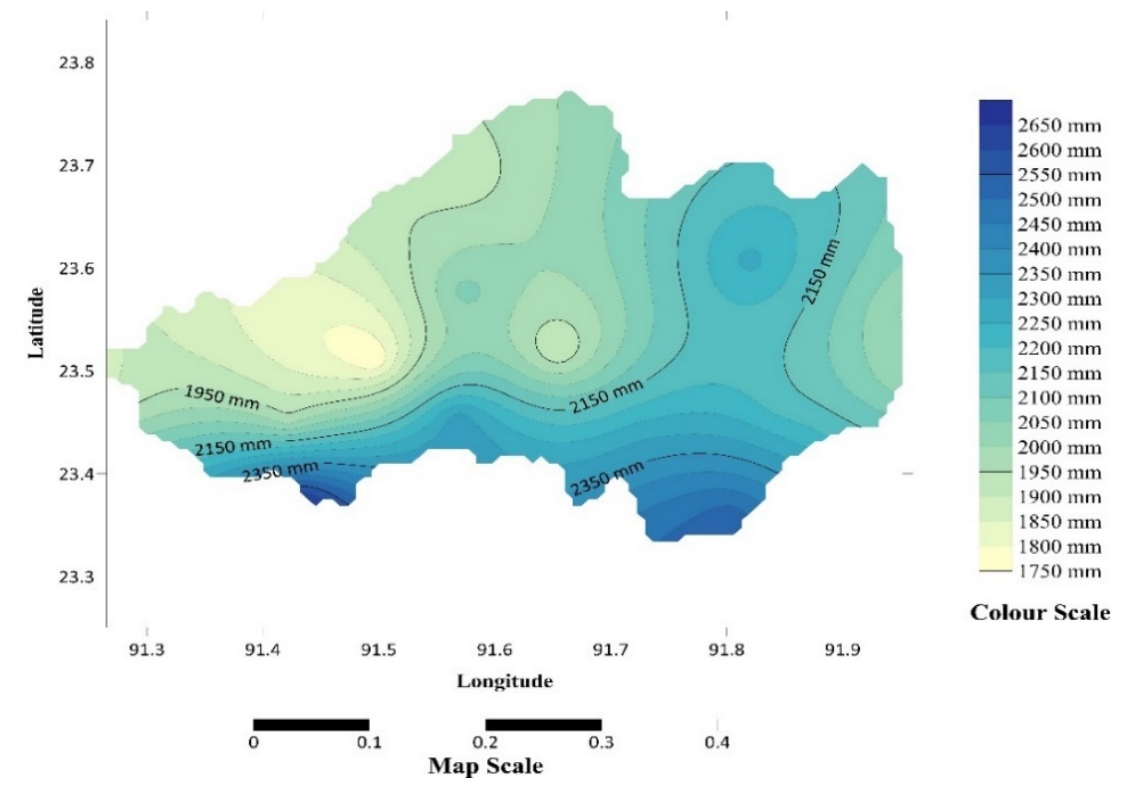

Figure 19: Graphical representation of isohyetal map of Gomati River Basin using downscaled grid wise average yearly rainfall data of 2031-2040 (Surfer 3D Modelling).

For the prediction of total flow of 2040s the best approach of total flow computation i.e. gridded approach is used. The average monthly flow and downscaled GCM data of whole Gomati Basin for 2031-2040 has been shown in figure 20 .

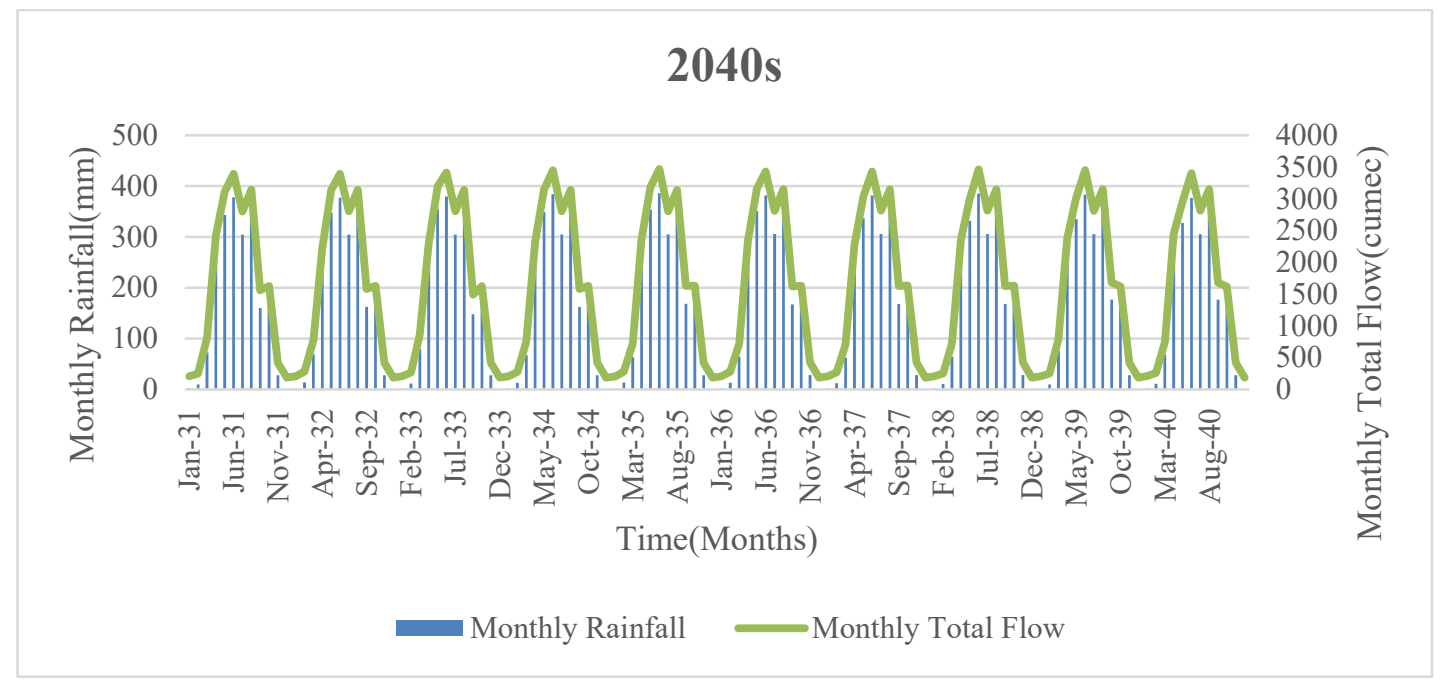

Figure 20: Graphical representation of monthly downscaled GCM data (2031-2040) and total flow for $2040 \mathrm{~s}$ 
The average yearly flow of whole Gomati Basin for 2040s has been shown in figure 21 .
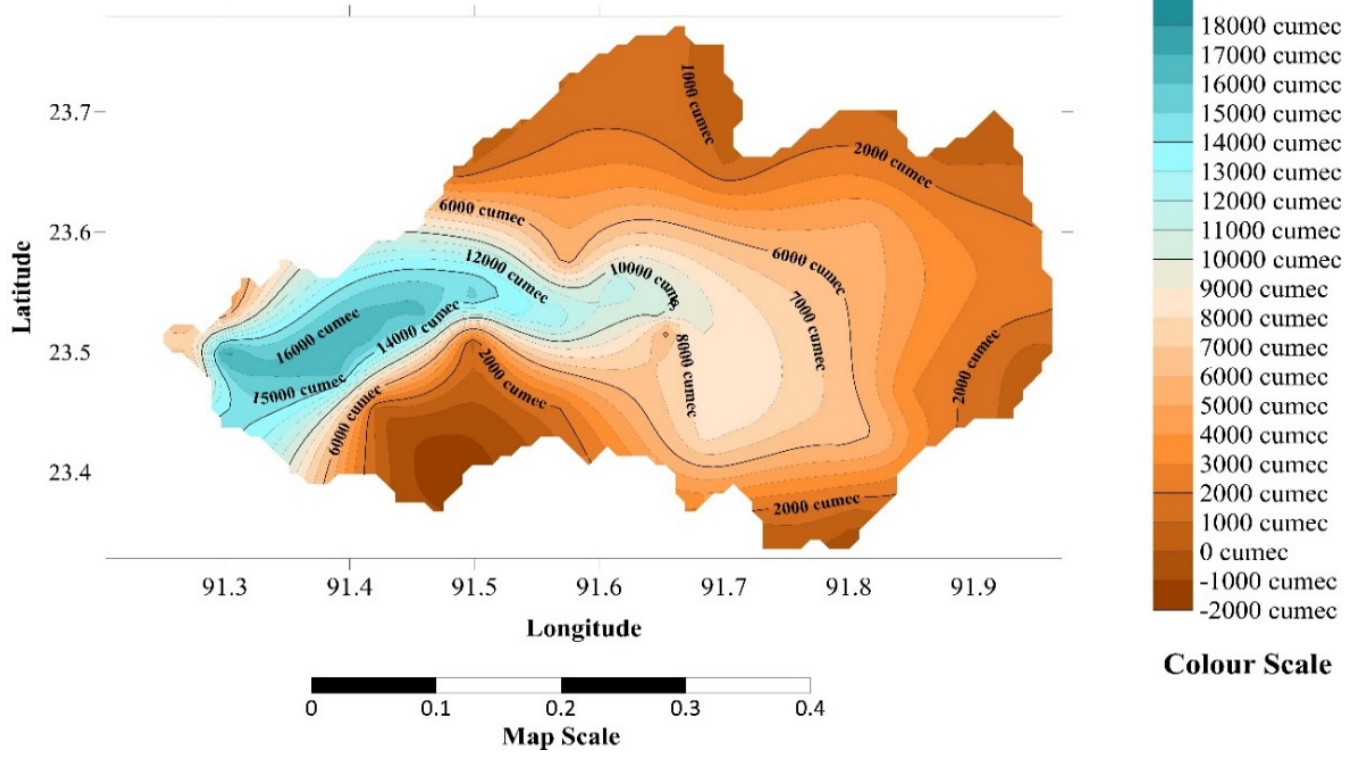

Figure 21: Graphical representation of the contour map of the total flow for 2040s on

\section{Gomati River Basin (Surfer 3D Modelling).}

3.10.3 Downscaled GCM Data and Total Flow of 2050s

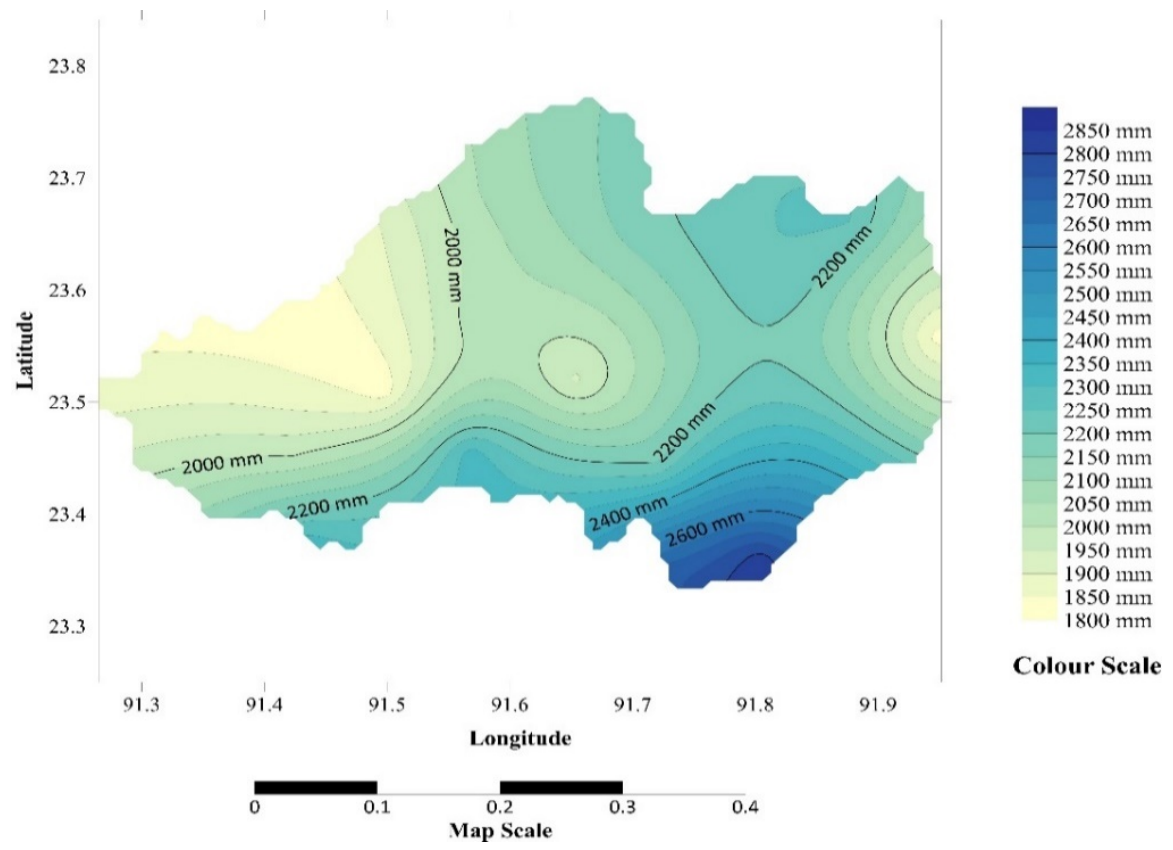

Figure 22: Graphical representation of isohyetal map of Gomati River Basin using downscaled grid wise average yearly rainfall data of 2041-2050 (Surfer 3D Modelling). 
For the prediction of total flow of 2050s the best approach of total flow computation i.e. gridded approach is used. The average monthly flow and downscaled GCM data of whole Gomati Basin for 2041-2050 has been shown in figure 23.

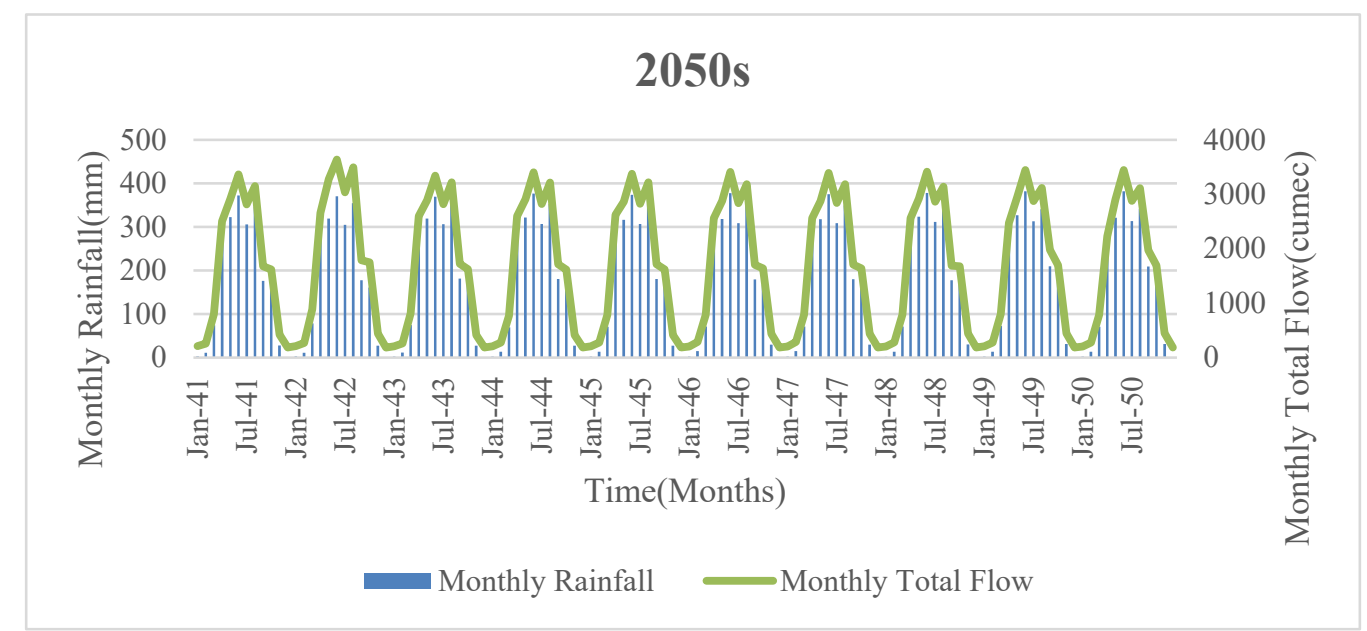

Figure 23: Graphical representation of monthly downscaled GCM data (2041-2050) and total flow for 2050s

The average yearly flow of whole Gomati Basin for 2050s has been shown in figure 24 .
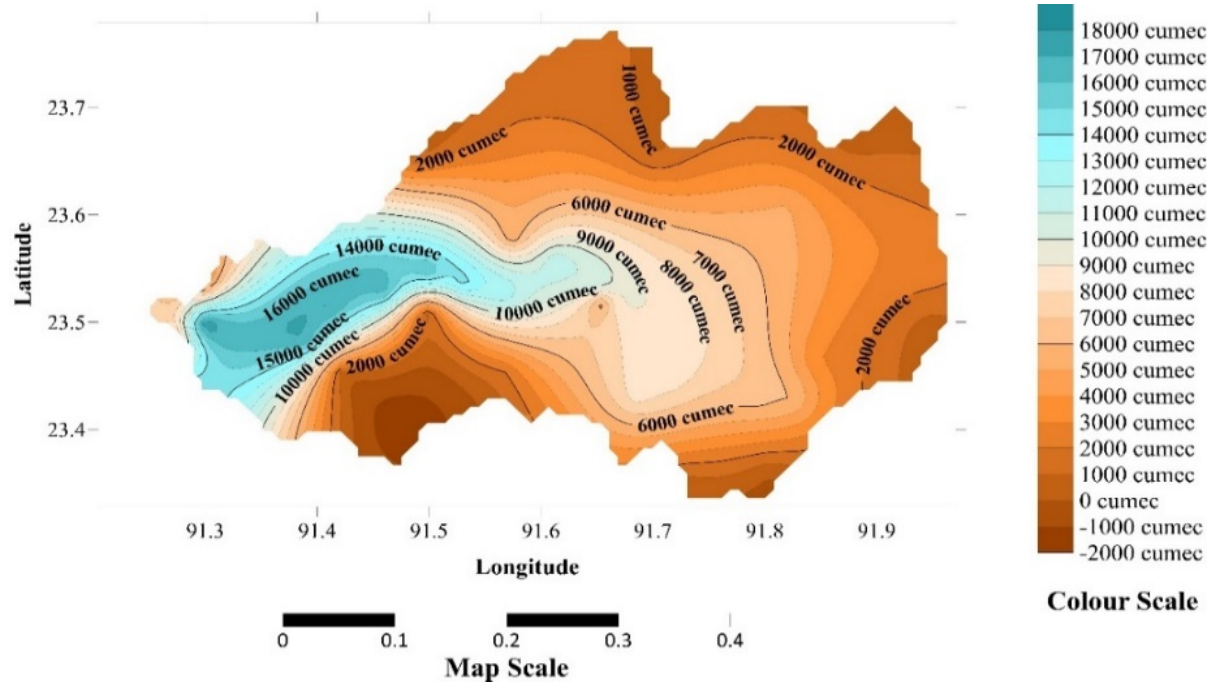

Colour Scale

Figure 24: Graphical representation of the contour map of the total flow for 2050s on Gomati River Basin (Surfer 3D Modelling). 


\subsection{Decade Wise Change in Flow}

The result of this study on Gomati River Basin shows that the average decade wise change in flow of 2020s (computed using converted IMD rainfall data with the help of Thiessen polygon), and predicted flow of 2030s, 2040s and 2050s decreases drastically with respect to the past decade 2010s. This change in flow has been shown graphically in figure 25 .

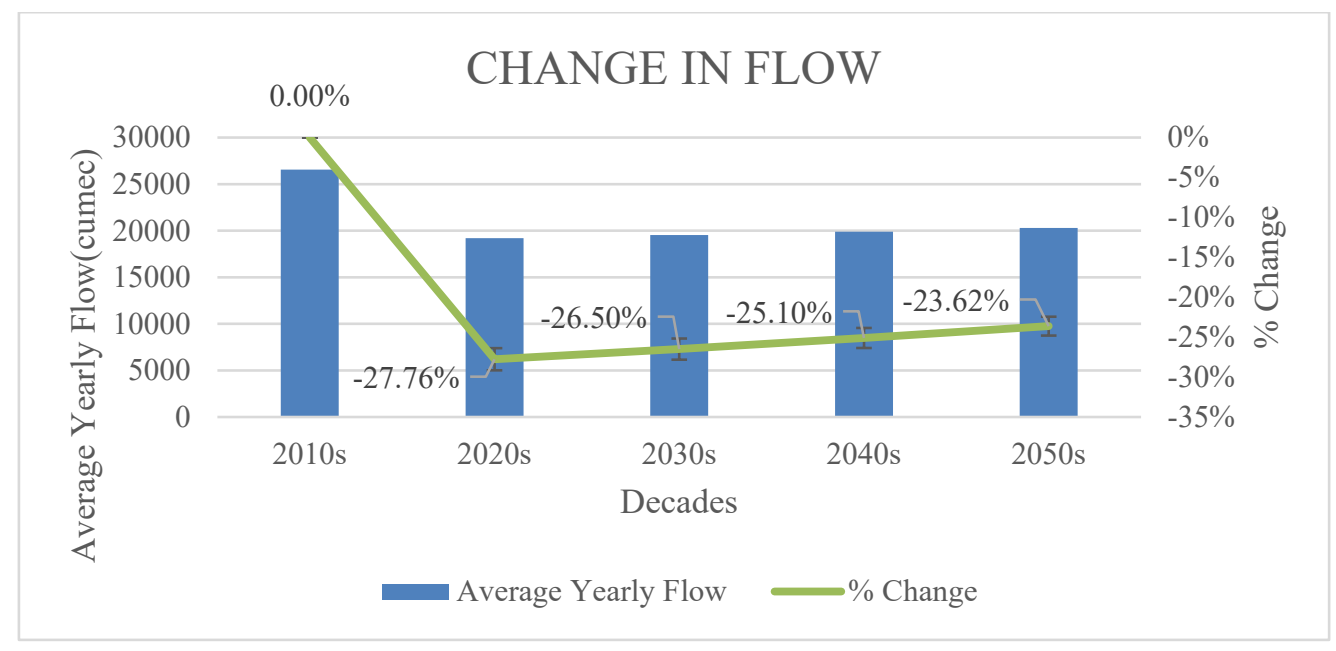

Figure 25: Graphical representation of change in flow of 2020s, 2030s, 2040s and 2050s with respect to the past decade 2010 s.

\section{Conclusion}

\subsection{Overall Conclusion}

Watershed area is delineated with the help of Google Earth Pro and the area of Gomati River Basin is obtained as $2205.04 \mathrm{~km}^{2}$. The whole watershed is divided into 19 grids of 15 $\mathrm{km} \times 15 \mathrm{~km}$. Grid wise land use land cover is calculated with the help of Geomatica FreeView. Area of settlement, forest, water body, agricultural land and barren land has been found as $1.47 \%, 62.22 \%, 4.82 \%, 30.54 \%$ and $0.99 \%$ of the total geographic area of Gomati River Basin. Using this grid wise land use data grid wise runoff coefficient has been computed and the composite runoff coefficient of Gomati Basin has been found as 0.328. A GMDH model has been developed considering the runoff coefficient, rainfall intensity, and area as inputs and the 
runoff as output and the GMDH model has been exported into a spreadsheet for the prediction of grid wise runoff of Gomati River basin.

The main aim of this study is to identify whether the climate change of this region has any impact on total flow of Gomati River Basin and if so, how much. The study has been conducted with the help of combining the GMDH model and HadGEM2-ES climate change model. The result of this study on Gomati River Basin shows that the average total flow of present decade 2020 s and future decades $2030 \mathrm{~s}, 2040$ s and 2050 s decreases $27.76 \%, 26.50 \%$, $25.10 \%$ and $23.62 \%$ respectively with respect to past decade 2010 s due to the fall of the volume of precipitation in present and future decades. It indicates that climate change can cause in a large reduction of precipitation, which further contributes to the reduction of total flow of Gomati River Basin.

\subsection{Scientific Benefits of the Study}

The scientific benefits of this study are the simulation results indicate that the decrease in precipitation has reduced the total flow significantly. This study provides water resources management authority and policy makers with a wide range of water resource availability projections data within the Gomati River basin. Other major benefits of this study are as follows

- A correlation between climate change impacts on rainfall-runoff of Gomati river basin can be bring out by this work.

- $\quad$ By analyzing the variations in rainfall-runoff data due to climate change could be beneficial for the output of the only hydroelectric power project of Tripura located at Dumboor on Gomati River.

- $\quad$ It could be also beneficial for the existing irrigation network based on Gomati River basin which could led to the increase in overall crop production of this state. 
- $\quad$ This work could be beneficial for the recent ambitious project of connecting waterways network between Gomati in Tripura and Meghna in Bangladesh.

\title{
4.3 Limitations and Future Scope
}

The findings of this study shows the future water resource availability of Gomati river basin, in the context of possible climate change scenarios, while acknowledging the high uncertainty in climate change projection. Future climate change would be the most important factor on water resource availability of this basin. In the downscaling method it was assumed, when the value of GCM data is zero then the downscaled value of GCM data will also be zero. Also future land use is a major factor in prediction of total flow, but it is almost impossible to predict the possible land use change in future.

The tool used for creating hydrological model is GMDH, other popular tool like SWAT is not used in this case, which could be more suitable for this river basin thus lead to a higher accuracy of model calibration and validation. And also REW approach like other innovative ungauged catchment method can be applied to find the same result and to observe the difference in present method and new methods. Also it is possible to know the water scarcity or availability of this basin if water demand data of this basin can be acquired. Lastly, if some other base flow method which is appropriate for the ungauged catchment can be used, then there may be a change in result.

\author{
Abbreviation \\ HEC-HMS = Hydrologic Engineering Centre-Hydrologic Modelling System \\ SWAT $=$ Soil and Water Assessment Tool \\ GMDH $=$ Group method of data handling \\ GCM $=$ General Circulation Model
}


REW $=$ Representative Elementary Watershed

MLR $=$ Multiple Linear Regression

PNN $=$ Polynomial Neural Network process

LMA $=$ Levenberg-Marquardt

GNA $=$ Gauss-Newton algorithm

$\mathrm{BP}=$ Back Propagation

HadGEM2 = Hadley Centre Global Environment Model version 2

IPCC $=$ Intergovernmental Panel on Climate Change

RCPs $=$ Representation Concentration Pathways

RMSE $=$ Root mean square error

MAE $=$ Mean Absolute Error

NES $=$ Nash-Sutcliffe Efficiency

PBIAS $=$ Percent Bias

$\mathrm{IMD}=$ India Meteorological Department

$\mathrm{CWC}=$ Central Water Commission 


\section{Declarations}

1. Ethical Approval:

- The manuscript should not be submitted to more than one journal for simultaneous consideration.

Answer: Not submitted.

- The submitted work should be original and should not have been published elsewhere in any form or language (partially or in full), unless the new work concerns an expansion of previous work. (Please provide transparency on the re-use of material to avoid the concerns about text-recycling ('self-plagiarism').

Answer: The submitted work is original and the work not has been published elsewhere.

- A single study should not be split up into several parts to increase the quantity of submissions and submitted to various journals or to one journal over time (i.e. 'salamislicing/publishing').

Answer: Not done.

- Concurrent or secondary publication is sometimes justifiable, provided certain conditions are met. Examples include: translations or a manuscript that is intended for a different group of readers.

Answer: Not applicable.

- Results should be presented clearly, honestly, and without fabrication, falsification or inappropriate data manipulation (including image based manipulation). Authors should adhere to discipline-specific rules for acquiring, selecting and processing data.

Answer: Results has been presented clearly, honestly, and without fabrication, falsification or inappropriate data manipulation (including image based manipulation). 
- No data, text, or theories by others are presented as if they were the author's own ('plagiarism'). Proper acknowledgements to other works must be given (this includes material that is closely copied (near verbatim), summarized and/or paraphrased), quotation marks (to indicate words taken from another source) are used for verbatim copying of material, and permissions secured for material that is copyrighted.

Answer: Not applicable.

- Authors should make sure they have permissions for the use of software, questionnaires/(web) surveys and scales in their studies (if appropriate).

Answer: Institute facility has been utilized with proper permission.

- Research articles and non-research articles (e.g. Opinion, Review, and Commentary articles) must cite appropriate and relevant literature in support of the claims made. Excessive and inappropriate self-citation or coordinated efforts among several authors to collectively self-cite is strongly discouraged.

Answer: All the above mentioned things has been done appropriately.

- Authors should avoid untrue statements about an entity (who can be an individual person or a company) or descriptions of their behavior or actions that could potentially be seen as personal attacks or allegations about that person.

Answer: Not applicable.

- Research that may be misapplied to pose a threat to public health or national security should be clearly identified in the manuscript (e.g. dual use of research). Examples include creation of harmful consequences of biological agents or toxins, disruption of immunity of vaccines, unusual hazards in the use of chemicals, weaponization of research/technology (amongst others).

Answer: Not applicable. 
- Authors are strongly advised to ensure the author group, the Corresponding Author, and the order of authors are all correct at submission. Adding and/or deleting authors during the revision stages is generally not permitted, but in some cases may be warranted. Reasons for changes in authorship should be explained in detail. Please note that changes to authorship cannot be made after acceptance of a manuscript.

Answer: All the above mentioned things has been done appropriately.

2. Consent to Participate:

All the authors has given their consent for participating in this research work.

3. Consent to Publish:

All the authors has given their consent for publishing this research work.

4. Authors contribution:

The study, concept and design, material preparation, data collection, analysis, writing of manuscript were performed by Debajit Das, Tilottama Chakraborty, Mrinmoy Majumder and Tarun Kanti Bandyopadhyay. All authors read and approved the final manuscript.

5. Funding:

No funding has been taken for this research study.

6. Competing Interests:

No conflict of interest for this present study.

7. Availability of data and materials:

Source of data has been clearly mentioned in the manuscript. 


\section{References}

1. Hadley Centre 1997 Climate change and its impacts: A global perspective; Department of the Environment, Transport and the Regions/Met. Office, Bracknell.

2. Ipcc Iii, W. G. "Third assessment report." Summary for policymakers.-2001 (2001).

3. Krishnan, R., J. Sanjay, Chellappan Gnanaseelan, Milind Mujumdar, Ashwini Kulkarni, and Supriyo Chakraborty. "Assessment of Climate Change over the Indian Region: A Report of the Ministry of Earth Sciences (MoES), Government of India." (2020): 226.

4. Kundzewicz, Zbigniew W., Luis Jose Mata, N. W. Arnell, Petra Doll, Pavel Kabat, Blanca Jimenez, Kathleen Miller, Taikan Oki, S. Zekai, and Igor Shiklomanov. "Freshwater resources and their management." (2007): 173-210.

5. Hunukumbura, P. B., and Yasuto Tachikawa. "River discharge projection under climate change in the Chao Phraya river basin, Thailand, using the MRI-GCM3. 1S dataset." Journal of the Meteorological Society of Japan. Ser. II 90 (2012): 137-150.

6. Kiem, Anthony S., Hiroshi Ishidaira, Hapuarachchige P. Hapuarachchi, Maichun C. Zhou, Yukiko Hirabayashi, and Kuniyoshi Takeuchi. "Future hydroclimatology of the Mekong River basin simulated using the high-resolution Japan Meteorological Agency (JMA) AGCM." Hydrological Processes: An International Journal 22, no. 9 (2008): 1382-1394.

7. Kim, Sunmin, Yasuto Tachikawa, Eiichi Nakakita, and Kaoru Takara. "Reconsideration of reservoir operations under climate change: case study with Yagisawa Dam, Japan." Annual Journal of Hydraulic Engineering, JSCE 53 (2009): 597-611.

8. Kim, Sunmin, Yasuto Tachikawa, Eiichi Nakakita, and Kaoru Takara. "Hydrologic evaluation on the AGCM20 output using observed river discharge data." Hydrological Research Letters 4 (2010): 35-39.

9. The Master Plan of Gumti Sub Basin, 1996. 
10. Jakeman, A. J., and G. M. Hornberger. "How much complexity is warranted in a rainfallrunoff model?" Water resources research 29, no. 8 (1993): 2637-2649.

11. Pachauri, Rajendra K., and Andy Reisinger. "Contribution of working groups I." II and III to the Fourth Assessment Report of the Intergovernmental Panel on Climate Change, IPCC, Geneva, Switzerland (2007): 104.

12. Moriasi, Daniel N., Jeffrey G. Arnold, Michael W. Van Liew, Ronald L. Bingner, R. Daren Harmel, and Tamie L. Veith. "Model evaluation guidelines for systematic quantification of accuracy in watershed simulations." Transactions of the ASABE 50, no. 3 (2007): 885-900.

13. Charley, William J. The hydrologic modeling system (HEC-HMS): Design and development issues. No. 149. US Army Corps of Engineers, Hydrologic Engineering Center, 1995.

14. "HEC-HMS"

traced from http://www.appsolutelydigital.com/ModelPrimer/chapter5_section2html on July 03, 2020.

15. Fu, LiMin, Hui-Huang Hsu, and Jose C. Principe. "Incremental backpropagation learning networks." IEEE Transactions on Neural Networks 7, no. 3 (1996): 757-761.

16. Fahlman, Scott E. An empirical study of learning speed in back-propagation networks. Carnegie Mellon University, Computer Science Department, 1988.

17. Marquardt, Donald W. "An algorithm for least-squares estimation of nonlinear parameters." Journal of the society for Industrial and Applied Mathematics 11, no. 2 (1963): 431-441.

18. Freedman, David A. Statistical models: theory and practice. cambridge university press, 2009.

19. Anastasakis, L., and N. Mort. "The development of self-organization techniques in modelling: a review of the group method of data handling (GMDH)." RESEARCH 
REPORT-UNIVERSITY OF SHEFFIELD DEPARTMENT OF AUTOMATIC CONTROL AND SYSTEMS ENGINEERING (2001).

20. Biswas, A. B., A. K. Saha, S. P. Dasgupta, and C. Chakraborty. "State of Environment of Tripura." Deptt. of Sc., Tech. and Env.. Govt of Tripura (1989).

21. De, Sunil Kumar. "GEO-ENVIRONMENTAL STATUS OF THE RIVER GUMTI, TRIPURA." Tripura State Pollution Control Board. ISSN: 2278-0181.

22. Jana, Bipal Kr, and Mrinmoy Majumder, eds. Impact of climate change on natural resource management. Springer Science \& Business Media, 2010.

23. Subramanya, K. Engineering Hydrology, 4e. Tata McGraw-Hill Education, 2013.

24. Collins, W. J., N. Bellouin, M. Doutriaux-Boucher, N. Gedney, P. Halloran, T. Hinton, J. Hughes et al. "Development and evaluation of an Earth-System modelHadGEM2." Geosci. Model Dev. Discuss 4, no. 2 (2011): 997-1062. 


\section{Figures}

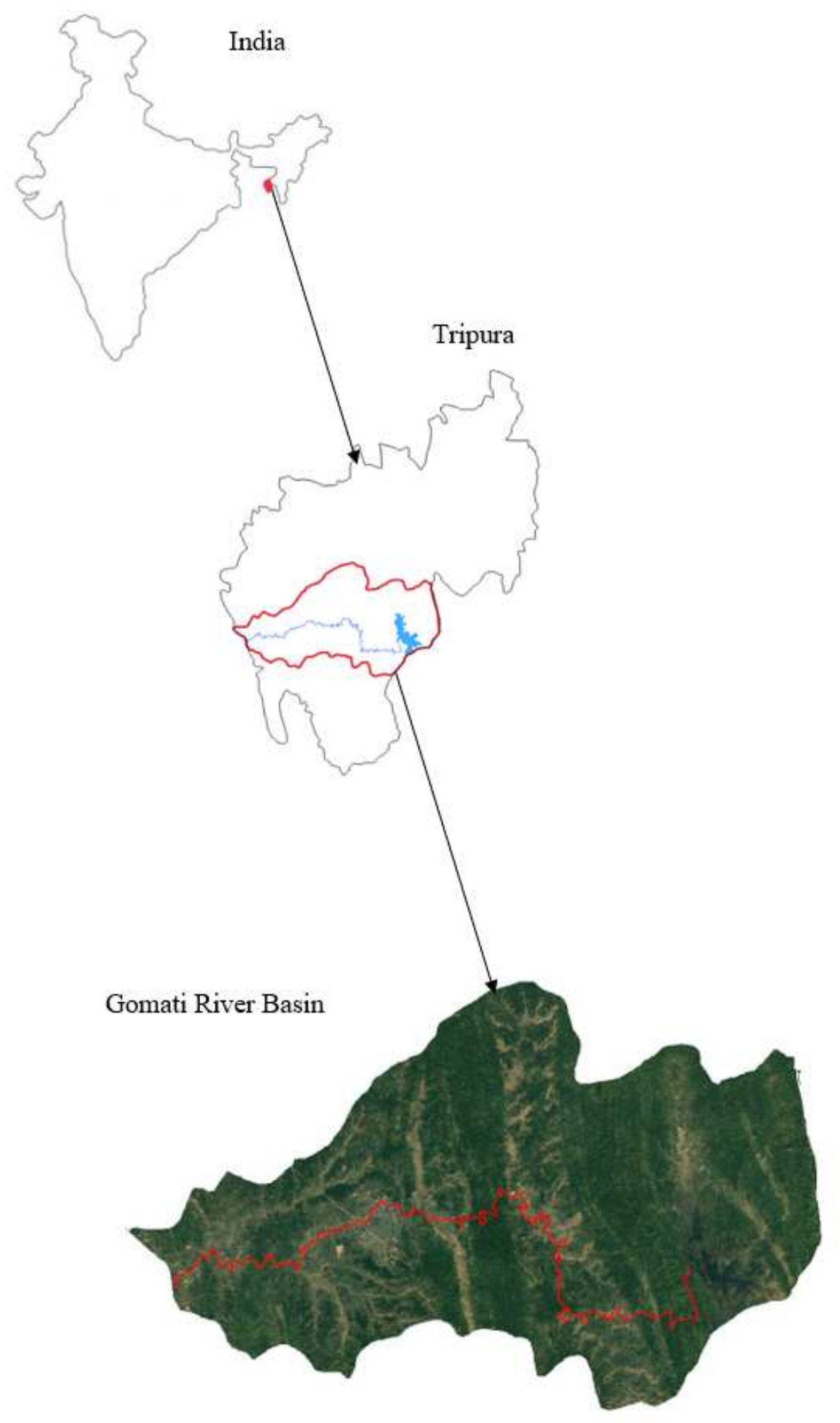

\section{Figure 1}

Study Area (Gomati River Basin) (Source: https://thumbs.dreamstime.com/b/print-173735639.jpg) Note: The designations employed and the presentation of the material on this map do not imply the expression of any opinion whatsoever on the part of Research Square concerning the legal status of any country, 
territory, city or area or of its authorities, or concerning the delimitation of its frontiers or boundaries. This map has been provided by the authors.

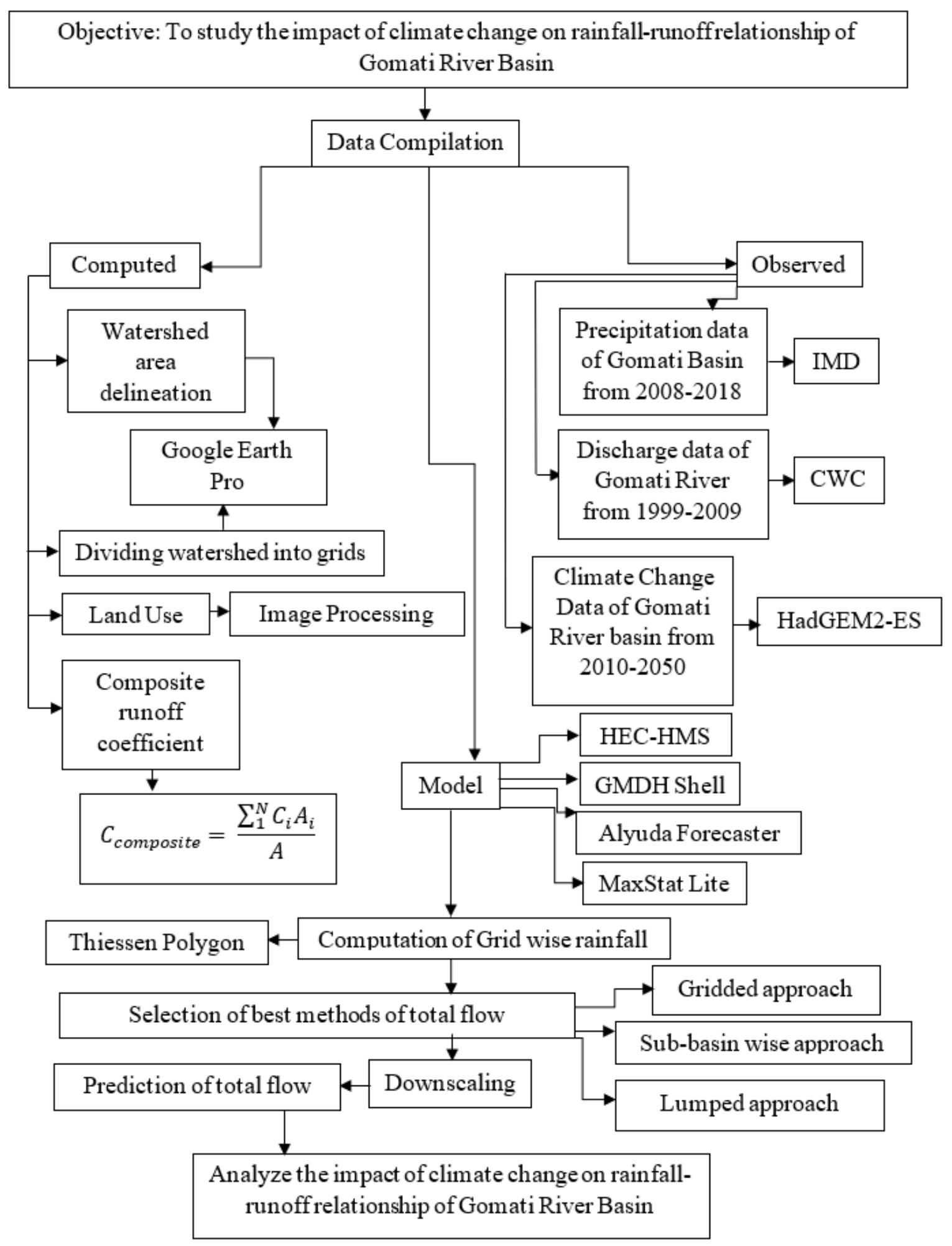

Figure 2

Flow chart showing the methodology of the present study objective 


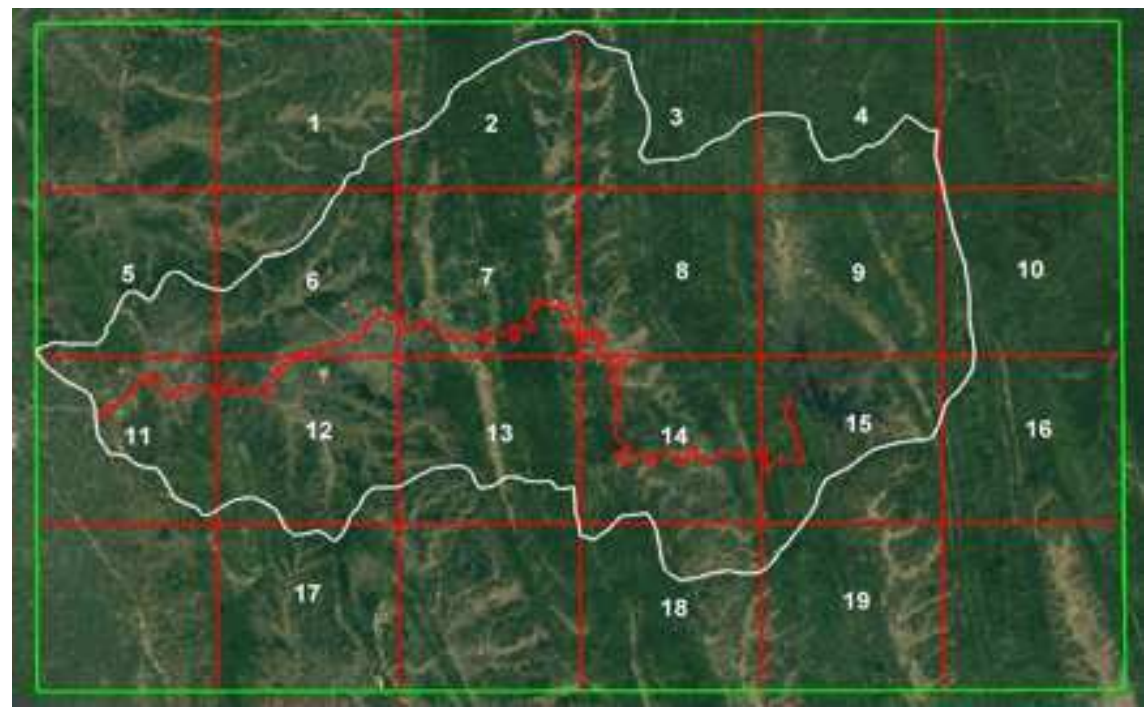

Figure 3

Gomati River Basin area with 19 grids of $15 \mathrm{~km} \times 15 \mathrm{~km}$ size. Note: The designations employed and the presentation of the material on this map do not imply the expression of any opinion whatsoever on the part of Research Square concerning the legal status of any country, territory, city or area or of its authorities, or concerning the delimitation of its frontiers or boundaries. This map has been provided by the authors.

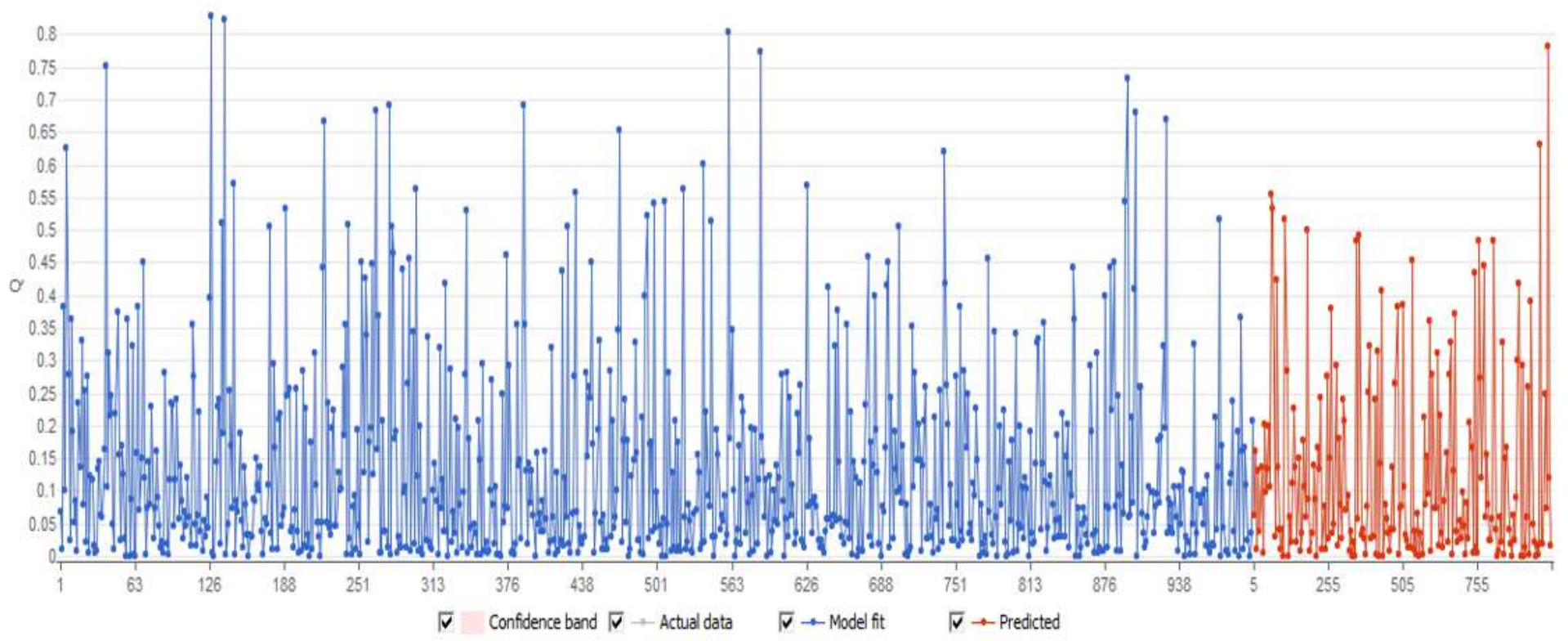

Figure 4

Showing the comparison for actual and predicted values of output 


\section{Rainfall Data from IMD (2008-2018)}

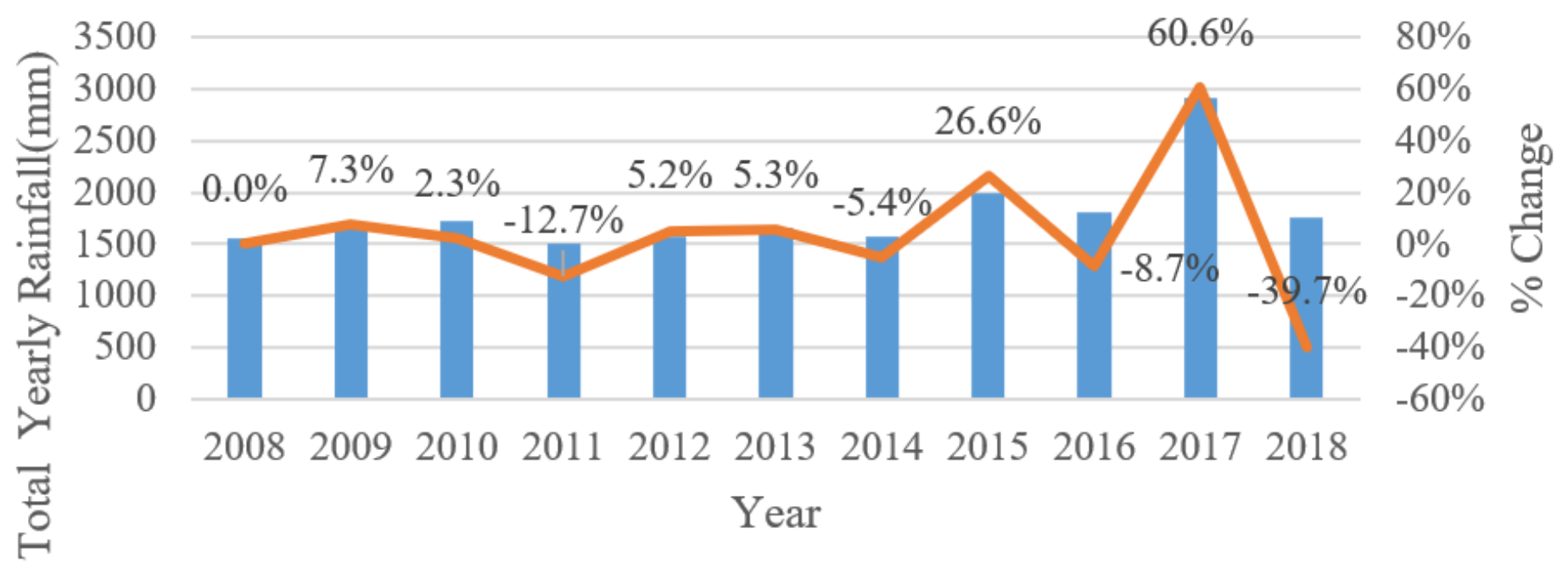

Rainfall $\%$ Change

Figure 5

Graphical representation of average observed rainfall data. 


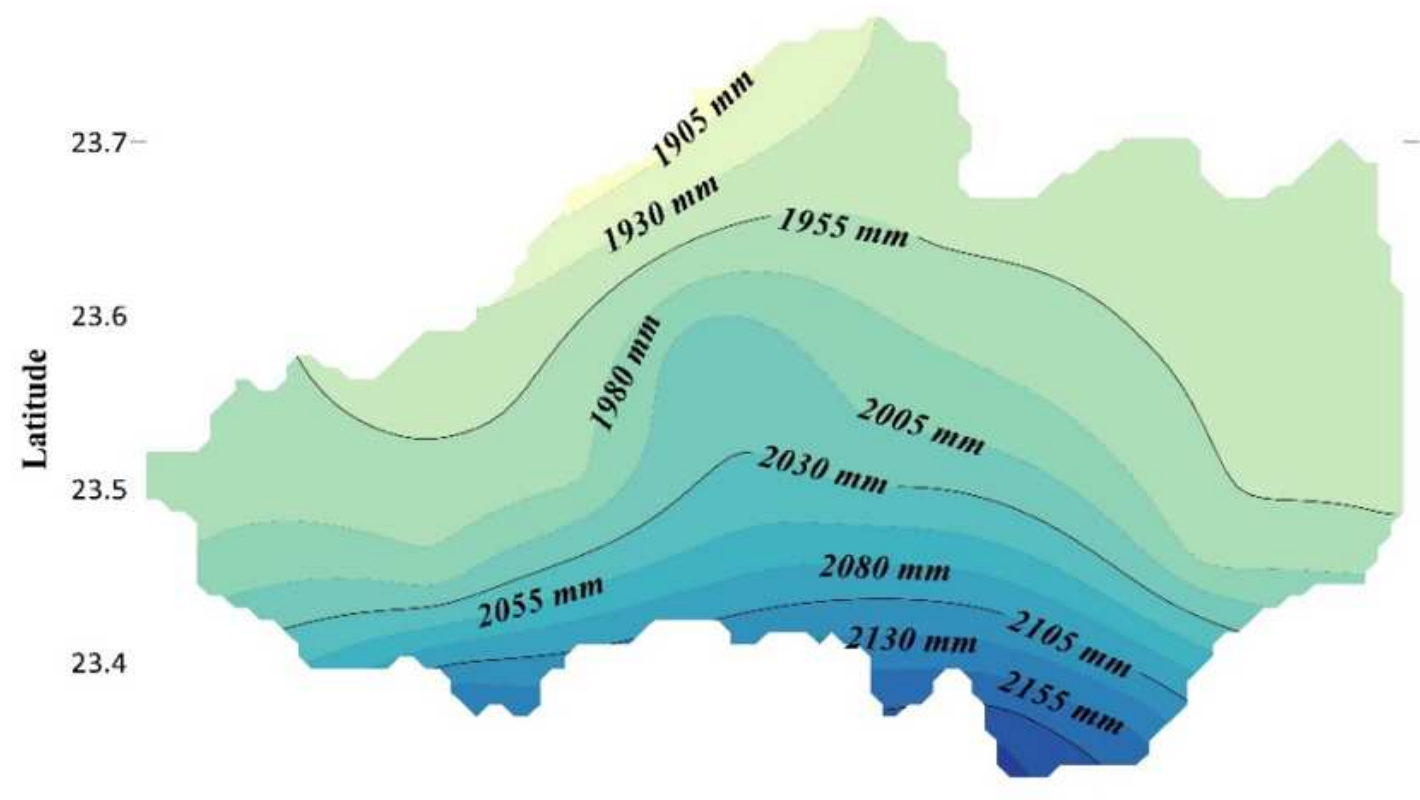

23.3
$2205 \mathrm{~mm}$ $2180 \mathrm{~mm}$ $2155 \mathrm{~mm}$ $2130 \mathrm{~mm}$ $2105 \mathrm{~mm}$ $2080 \mathrm{~mm}$ $2055 \mathrm{~mm}$ $2030 \mathrm{~mm}$ $2005 \mathrm{~mm}$ $1980 \mathrm{~mm}$ $1955 \mathrm{~mm}$ $1930 \mathrm{~mm}$ $1905 \mathrm{~mm}$ $1880 \mathrm{~mm}$

\section{Colour Scale}

$\begin{array}{ccccccc}91.3 & 91.4 & 91.5 & \begin{array}{c}91.6 \\ \text { Longitude }\end{array} & 91.7 & 91.8 & 91.9 \\ & 0.1 & \begin{array}{c}0.2 \\ \text { Map Scale }\end{array} & 0.3 & 0.4 & \end{array}$

\section{Figure 6}

Graphical representation of isohyetal map of Gomati River Basin using computed grid wise average yearly rainfall data of 2008-2018 (Surfer 3D Modelling). Note: The designations employed and the presentation of the material on this map do not imply the expression of any opinion whatsoever on the part of Research Square concerning the legal status of any country, territory, city or area or of its authorities, or concerning the delimitation of its frontiers or boundaries. This map has been provided by the authors. 


\section{Computation of error for grided approach}
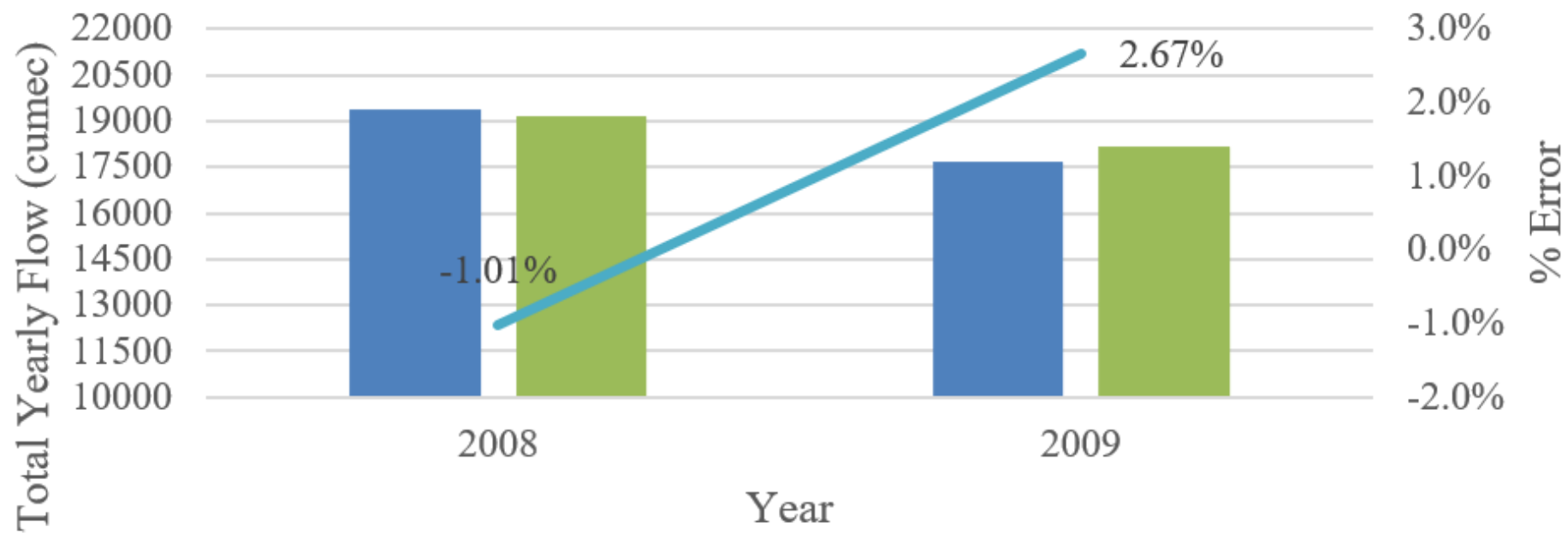

Year

Observed Total Flow (CWC) $\quad$ Comptuted Total Flow $\quad \%$ Error

\section{Figure 7}

Graphical representation of observed total flow (CWC), computed total flow (gridded approach) and \% error.

\section{Computation of error for station wise approach}

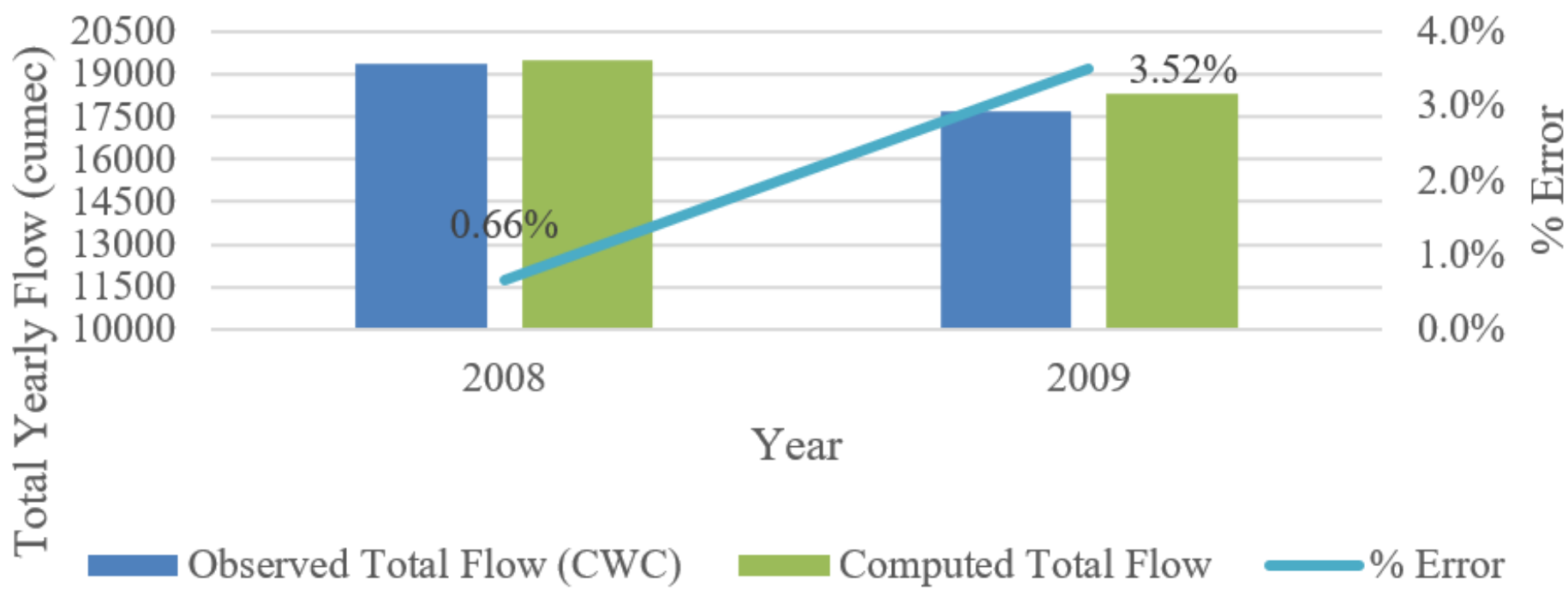

\section{Figure 8}

Graphical representation of observed total flow (CWC), computed total flow (sub-basin approach) and \% error. 


\section{Computation of error for lumped approach}

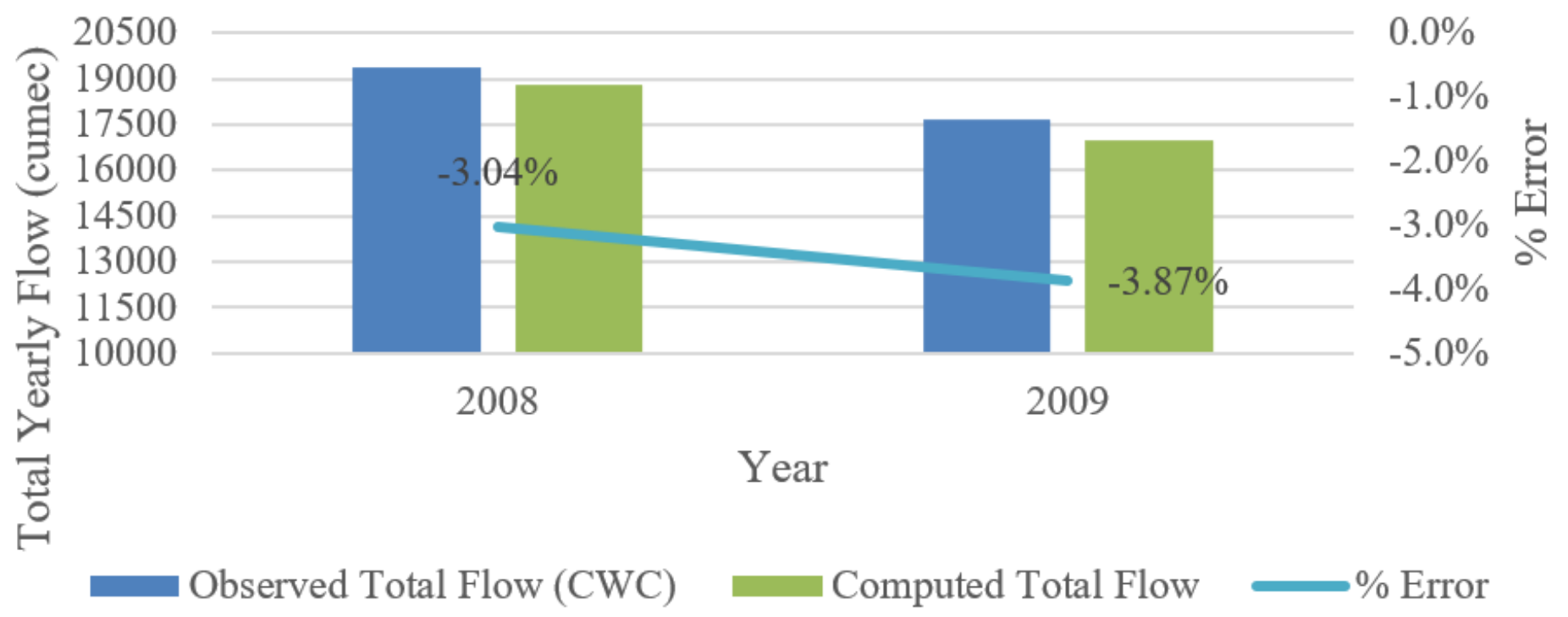

\section{Figure 9}

Graphical representation of observed total flow (CWC), computed total flow (lumped approach) and \% error.

\section{Observed Data vs GCM Data}

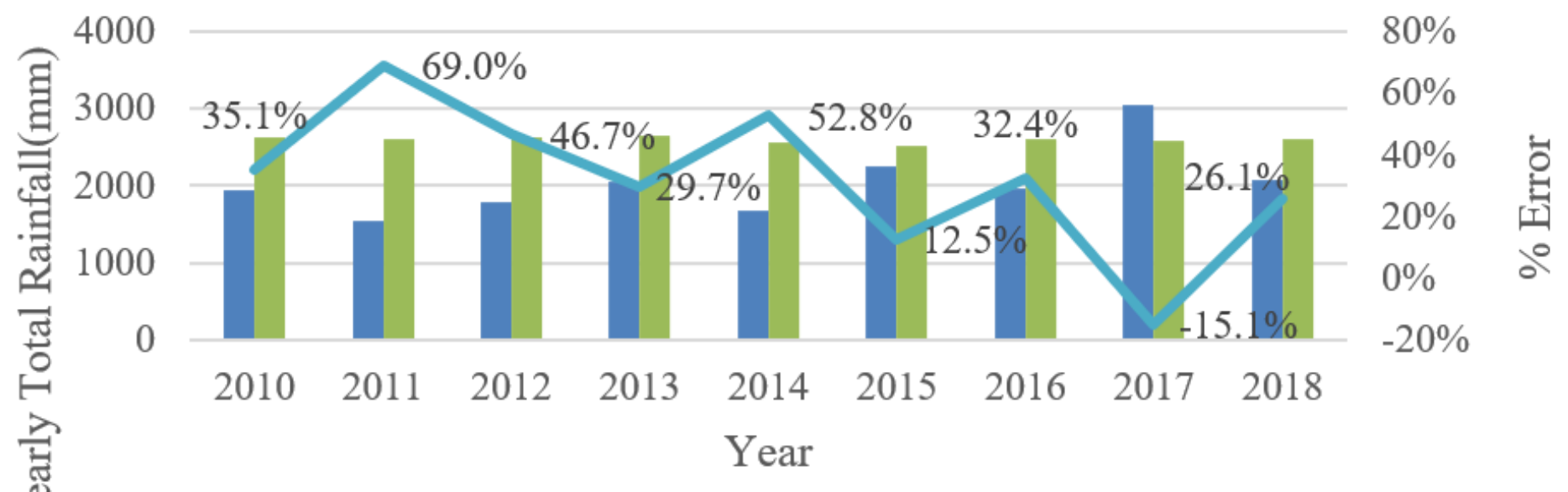

Observed GCM $\longrightarrow$ Error

Figure 10

Graphical representation of variation in GCM data (2010-2018) with respect to observed data (20102018). 


\section{Observed Data vs Downscaled GCM Data}

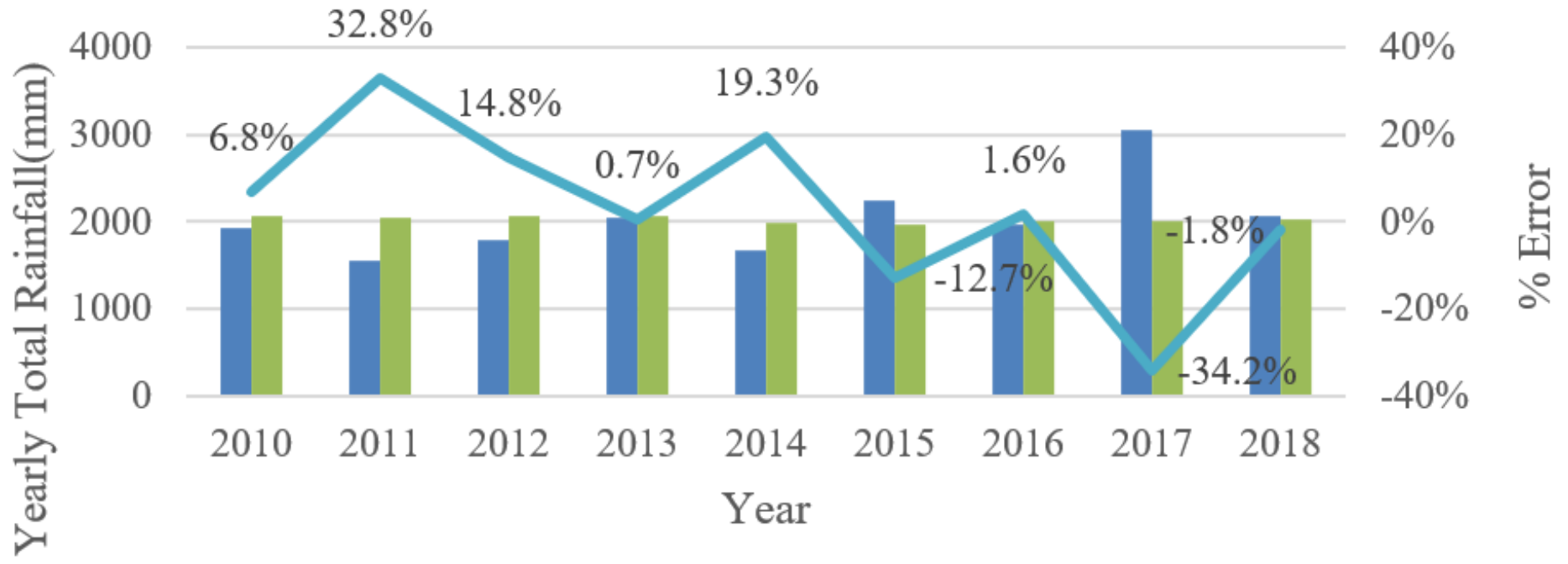

Observed Downscaled $\quad \%$ Error

\section{Figure 11}

Graphical representation of variation in downscaled GCM data (2010-2018) with respect to observed data (2010-2018). 
23.8

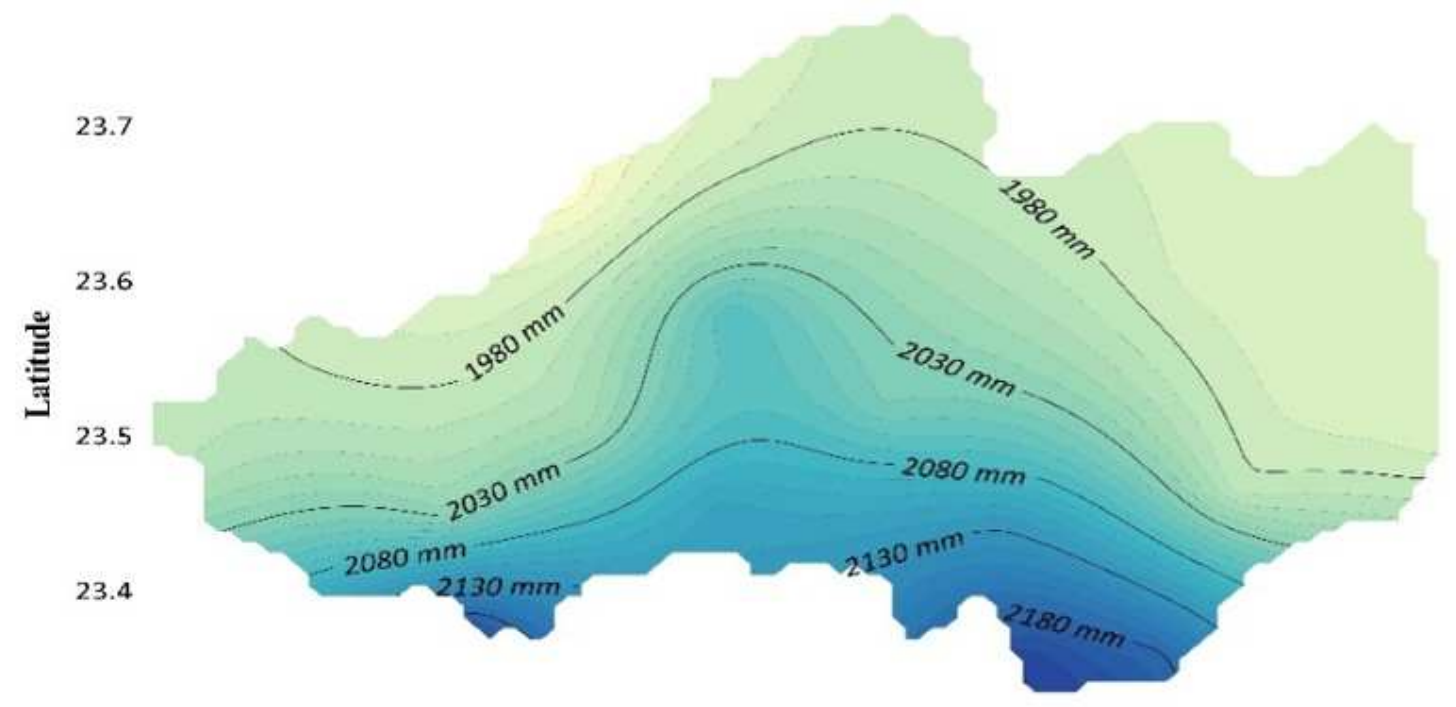

23.3

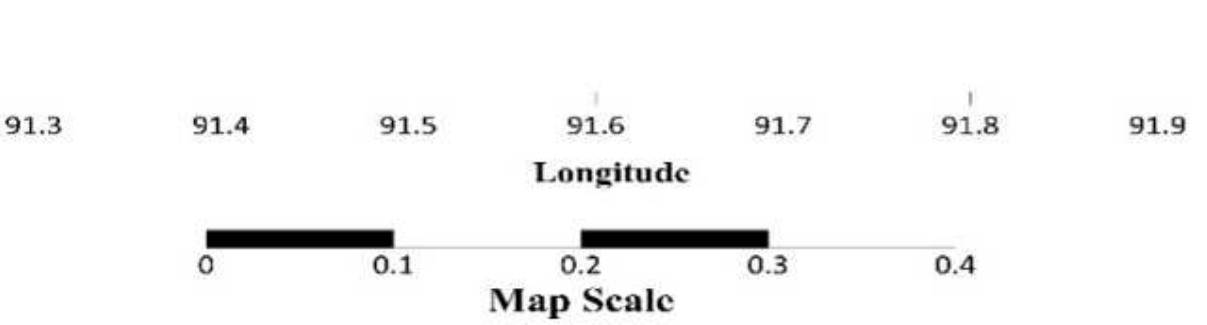

\section{Figure 12}

Graphical representation of isohyetal map of Gomati River Basin using downscaled grid wise average yearly rainfall data of 2010-2018 (Surfer 3D Modelling). Note: The designations employed and the presentation of the material on this map do not imply the expression of any opinion whatsoever on the part of Research Square concerning the legal status of any country, territory, city or area or of its authorities, or concerning the delimitation of its frontiers or boundaries. This map has been provided by the authors. 


\section{Monthly Rainfall for 2030s}

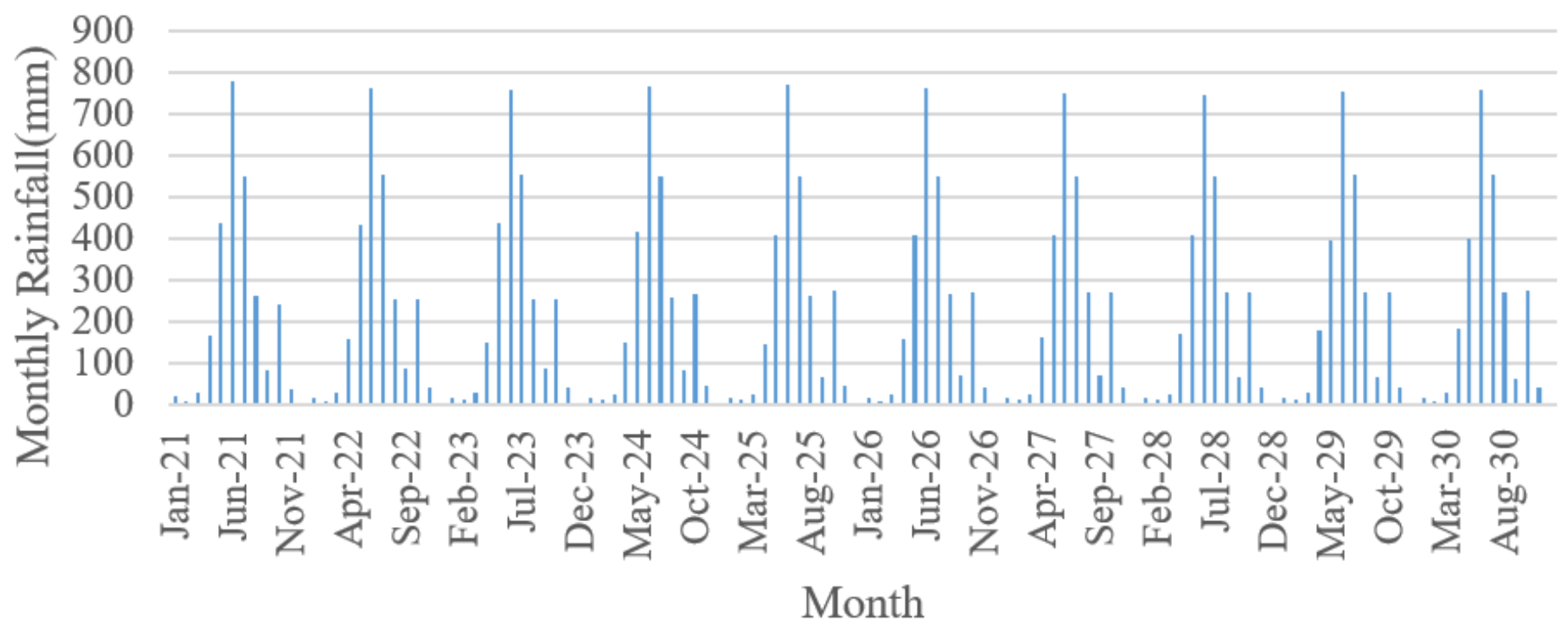

Figure 13

Graphical representation of monthly GCM data (2021-2030)

\section{Monthly Rainfall for 2040s}

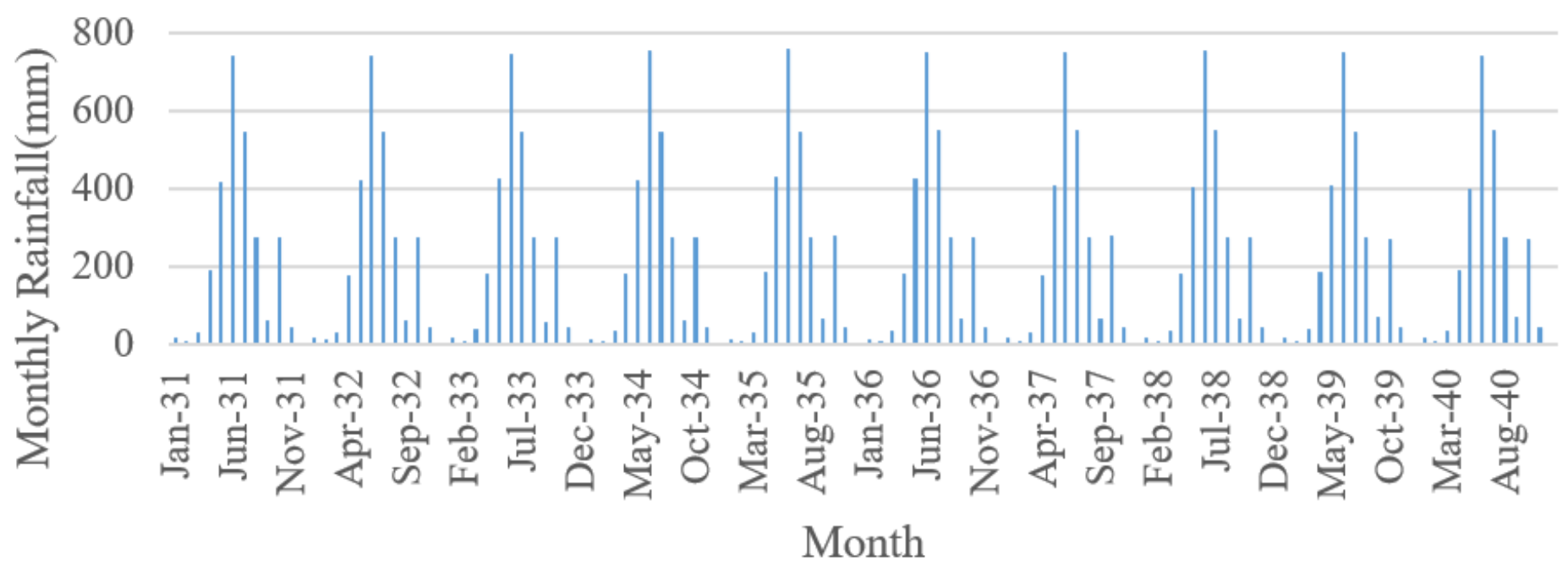

Figure 14

Graphical representation of monthly GCM data (2031-2040) 


\section{Monthly Rainfall for 2050s}

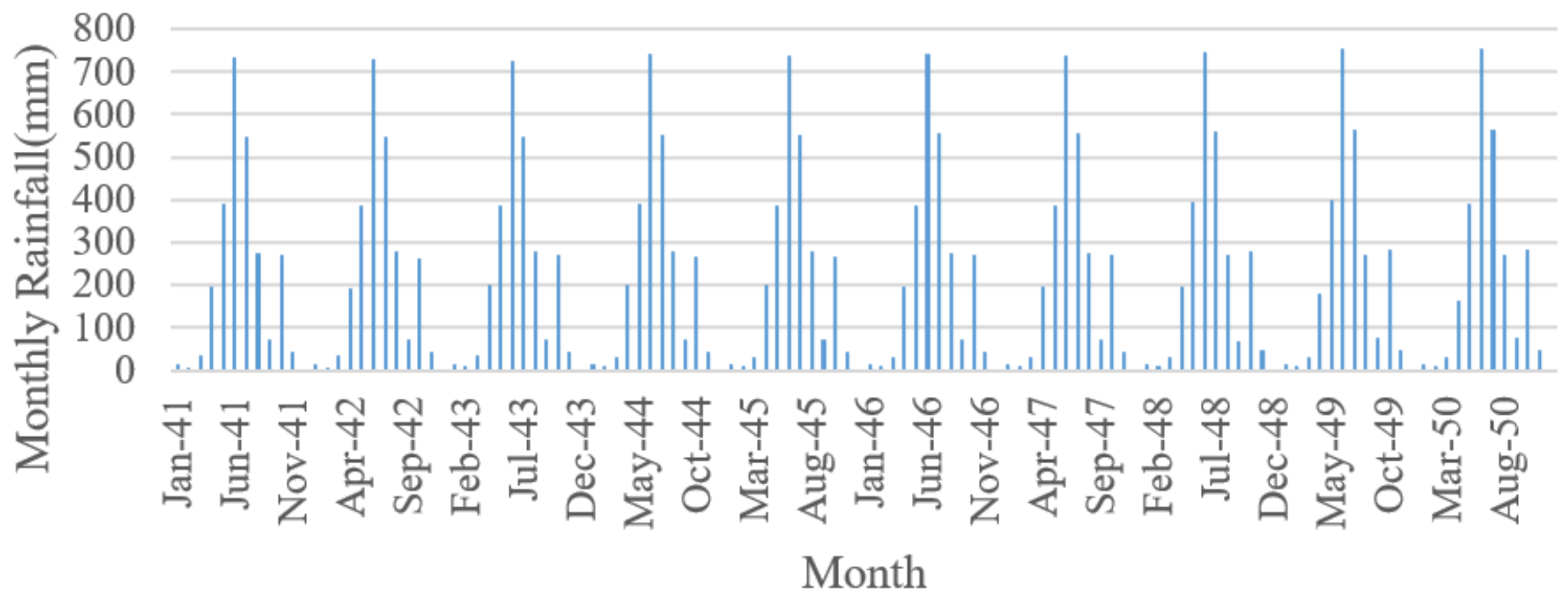

Figure 15

Graphical representation of monthly GCM data (2041-2050)

23.8

23.7

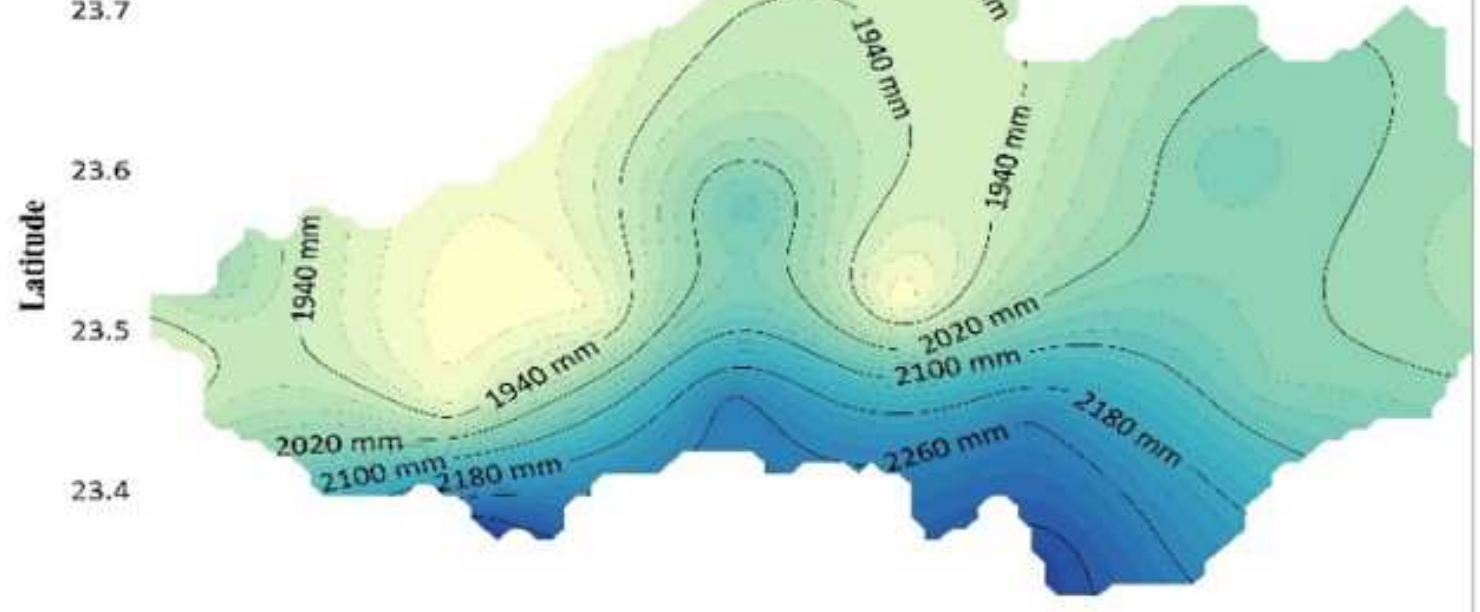

23.3

91.3

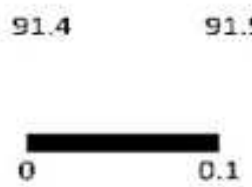

91.5

91.6

91.7

91.8

91.9

$2380 \mathrm{~mm}$

$2340 \mathrm{~mm}$

$2300 \mathrm{~mm}$

$2260 \mathrm{~mm}$

$2220 \mathrm{~mm}$

$2180 \mathrm{~mm}$

$2140 \mathrm{~mm}$

$2100 \mathrm{~mm}$

$2060 \mathrm{~mm}$

$2020 \mathrm{~mm}$

$1980 \mathrm{~mm}$

$1940 \mathrm{~mm}$

$1900 \mathrm{~mm}$

$1860 \mathrm{~mm}$

Colour Scale

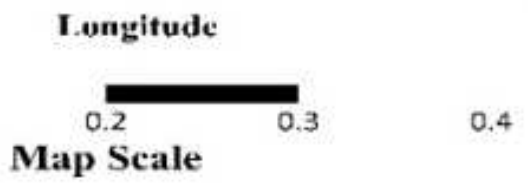


Figure 16

Graphical representation of isohyetal map of Gomati River Basin using downscaled grid wise average yearly rainfall data of 2021-2030 (Surfer 3D Modelling). Note: The designations employed and the presentation of the material on this map do not imply the expression of any opinion whatsoever on the part of Research Square concerning the legal status of any country, territory, city or area or of its authorities, or concerning the delimitation of its frontiers or boundaries. This map has been provided by the authors.

\section{0s}

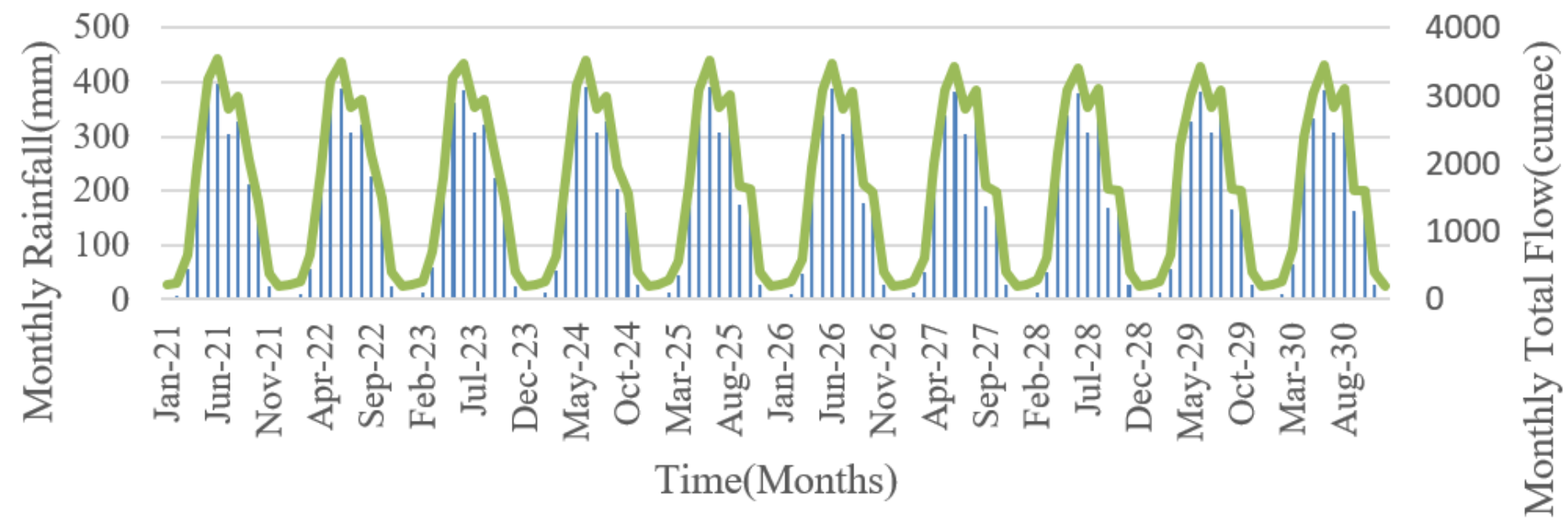

Monthly Rainfall Monthly Total Flow

Figure 17

Graphical representation of monthly downscaled GCM data (2021-2030) and total flow for 2030s 
23.7

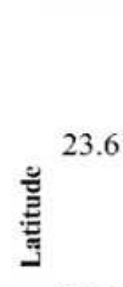

23.5

23.4

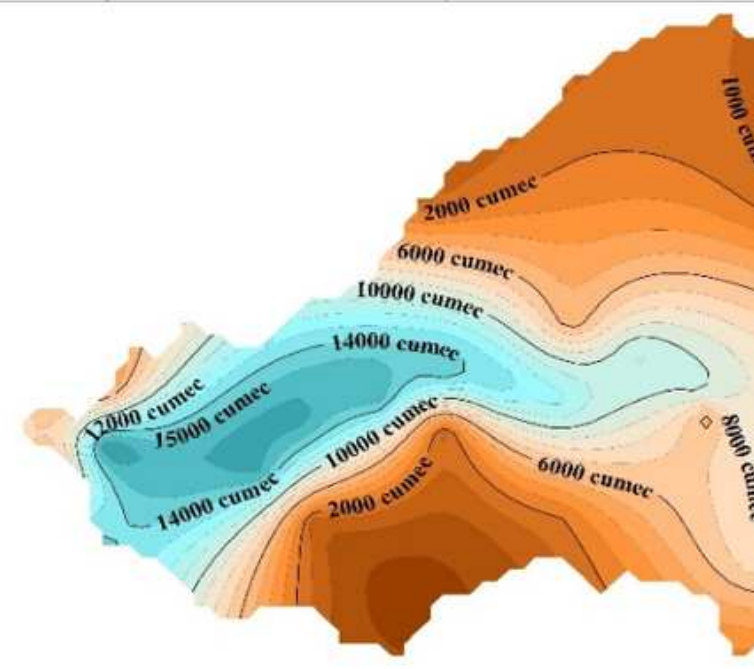

91.3

91.4

91.5

91.6

91.7

Longitude

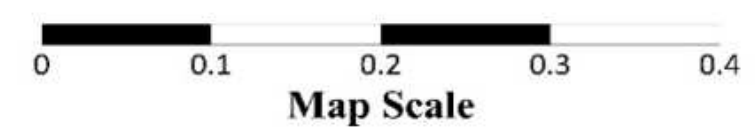

17000 cumec 16000 cumec 15000 cumec 14000 cumec 13000 cumcc 12000 cumec 11000 cumcc 10000 cumec 9000 cumce 8000 cumec 7000 cumec 6000 cumec 5000 cumec 4000 cumec 3000 cumec 2000 cumec 1000 cumec 0 cumec -1000 cumec -2000 cumcc

\section{Colour Scale}

\section{Figure 18}

Graphical representation of the contour map of the total flow for 2030s on Gomati River Basin (Surfer 3D Modelling). Note: The designations employed and the presentation of the material on this map do not imply the expression of any opinion whatsoever on the part of Research Square concerning the legal status of any country, territory, city or area or of its authorities, or concerning the delimitation of its frontiers or boundaries. This map has been provided by the authors. 


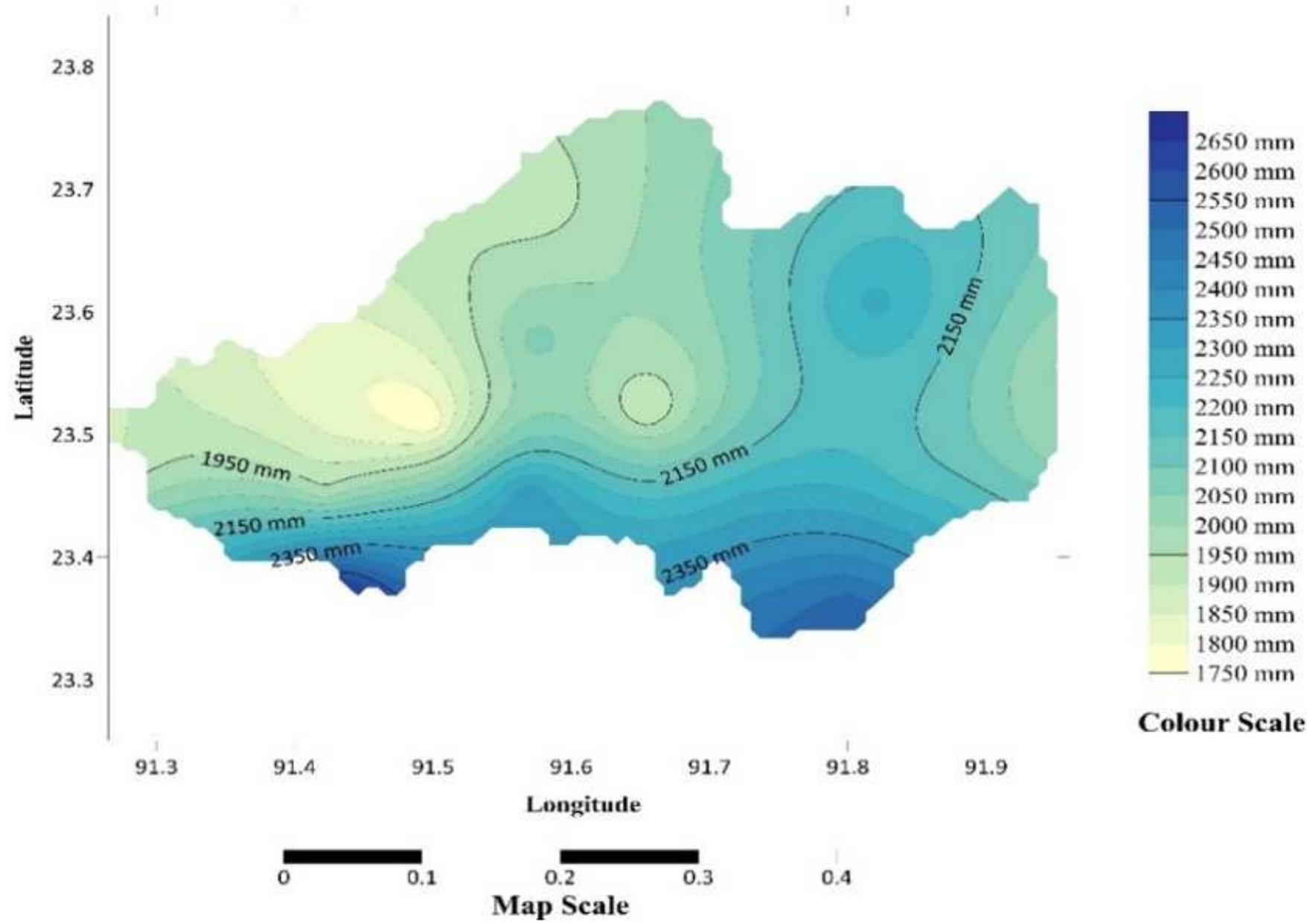

Figure 19

Graphical representation of isohyetal map of Gomati River Basin using downscaled grid wise average yearly rainfall data of 2031-2040 (Surfer 3D Modelling). Note: The designations employed and the presentation of the material on this map do not imply the expression of any opinion whatsoever on the part of Research Square concerning the legal status of any country, territory, city or area or of its authorities, or concerning the delimitation of its frontiers or boundaries. This map has been provided by the authors. 


\section{0s}

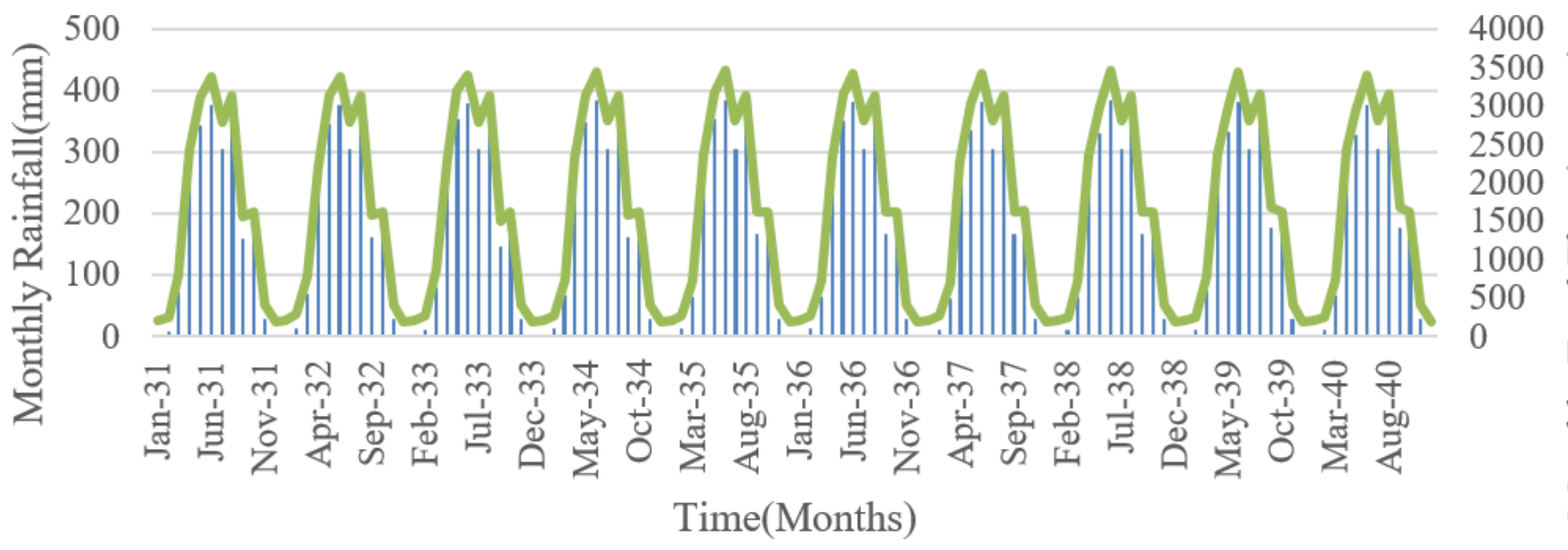

Monthly Rainfall $\longrightarrow$ Monthly Total Flow

Figure 20

Graphical representation of monthly downscaled GCM data (2031-2040) and total flow for 2040s

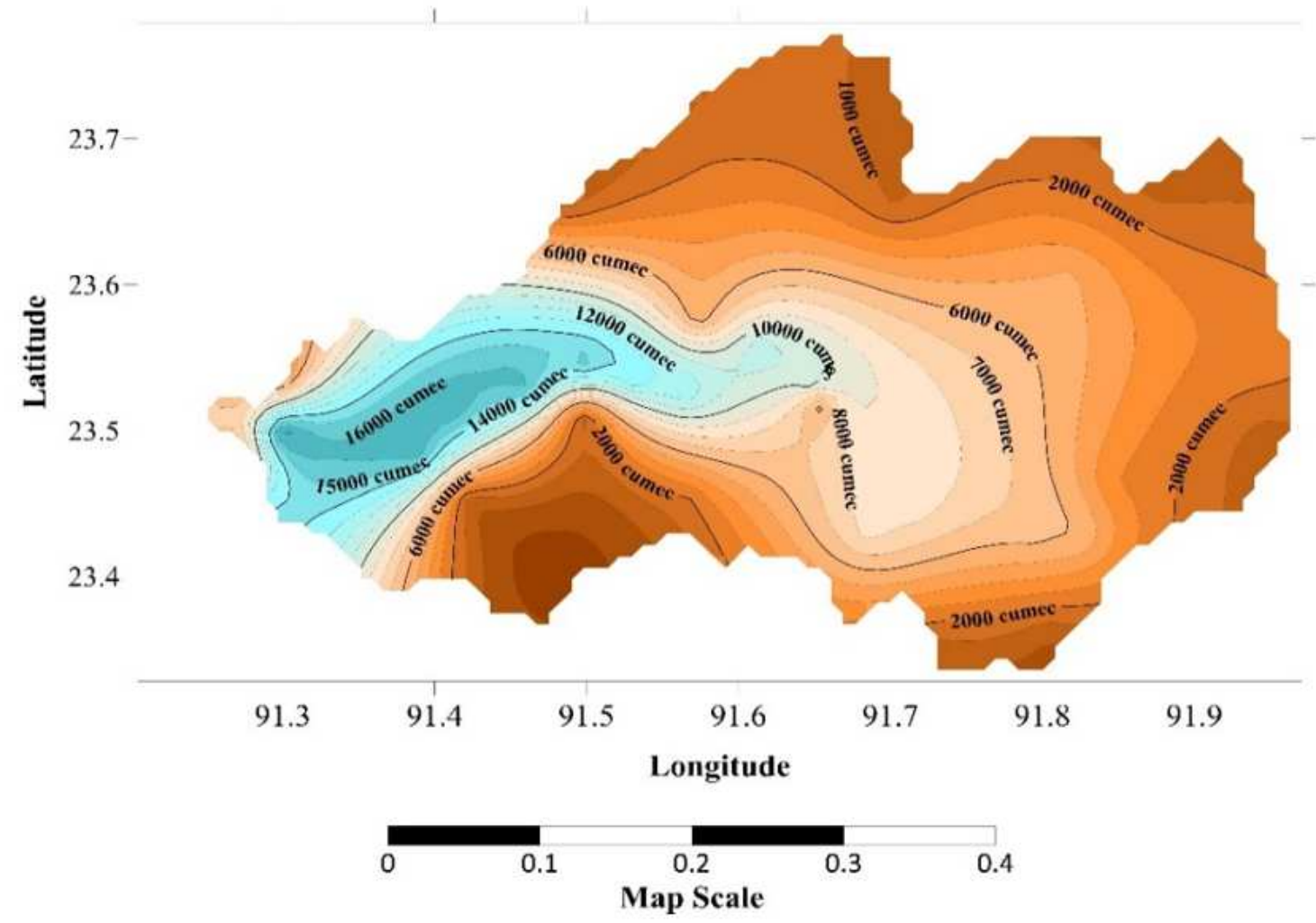

18000 cumec 17000 cumec 16000 cumec 15000 cumec 14000 cumec 13000 cumec 12000 cumec 11000 cumec 10000 cumec 9000 cumec 8000 cumec 7000 cumec 6000 cumec 5000 cumec 4000 cumec 3000 cumec 2000 cumec 1000 cumec 0 cumec -1000 cumec -2000 cumec

\section{Colour Scale}

Figure 21 
Graphical representation of the contour map of the total flow for 2040s on Gomati River Basin (Surfer 3D Modelling). Note: The designations employed and the presentation of the material on this map do not imply the expression of any opinion whatsoever on the part of Research Square concerning the legal status of any country, territory, city or area or of its authorities, or concerning the delimitation of its frontiers or boundaries. This map has been provided by the authors.

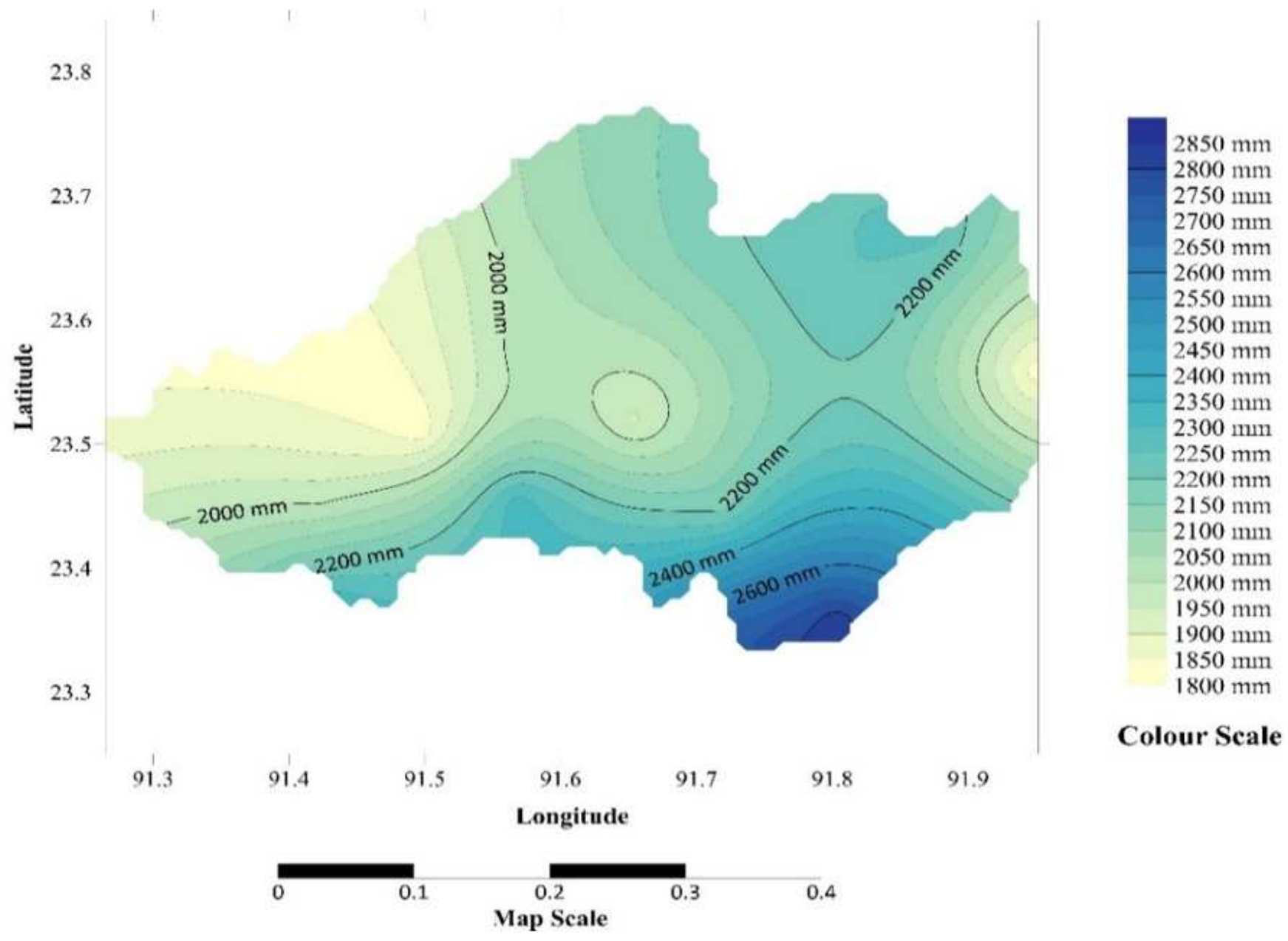

Figure 22

Graphical representation of isohyetal map of Gomati River Basin using downscaled grid wise average yearly rainfall data of 2041-2050 (Surfer 3D Modelling). Note: The designations employed and the presentation of the material on this map do not imply the expression of any opinion whatsoever on the part of Research Square concerning the legal status of any country, territory, city or area or of its authorities, or concerning the delimitation of its frontiers or boundaries. This map has been provided by the authors. 


\section{0s}

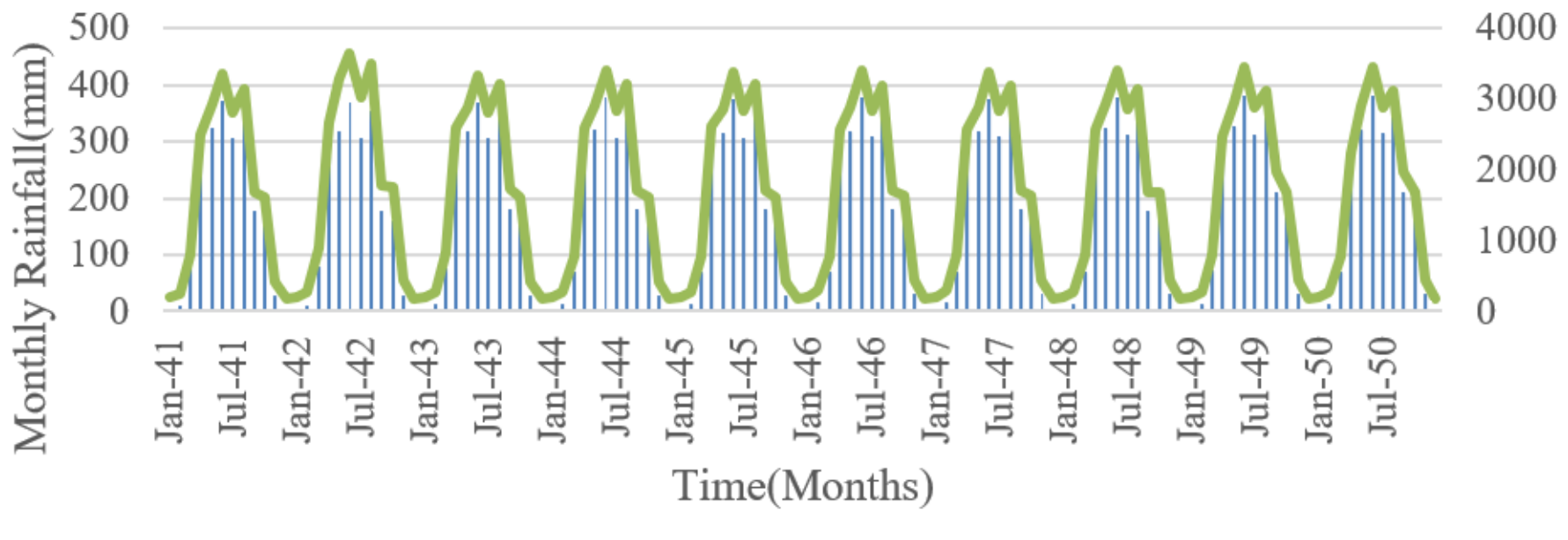

Monthly Rainfall $\quad$ Monthly Total Flow

Figure 23

Graphical representation of monthly downscaled GCM data (2041-2050) and total flow for 2050s

23.7

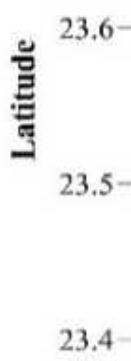

23.4

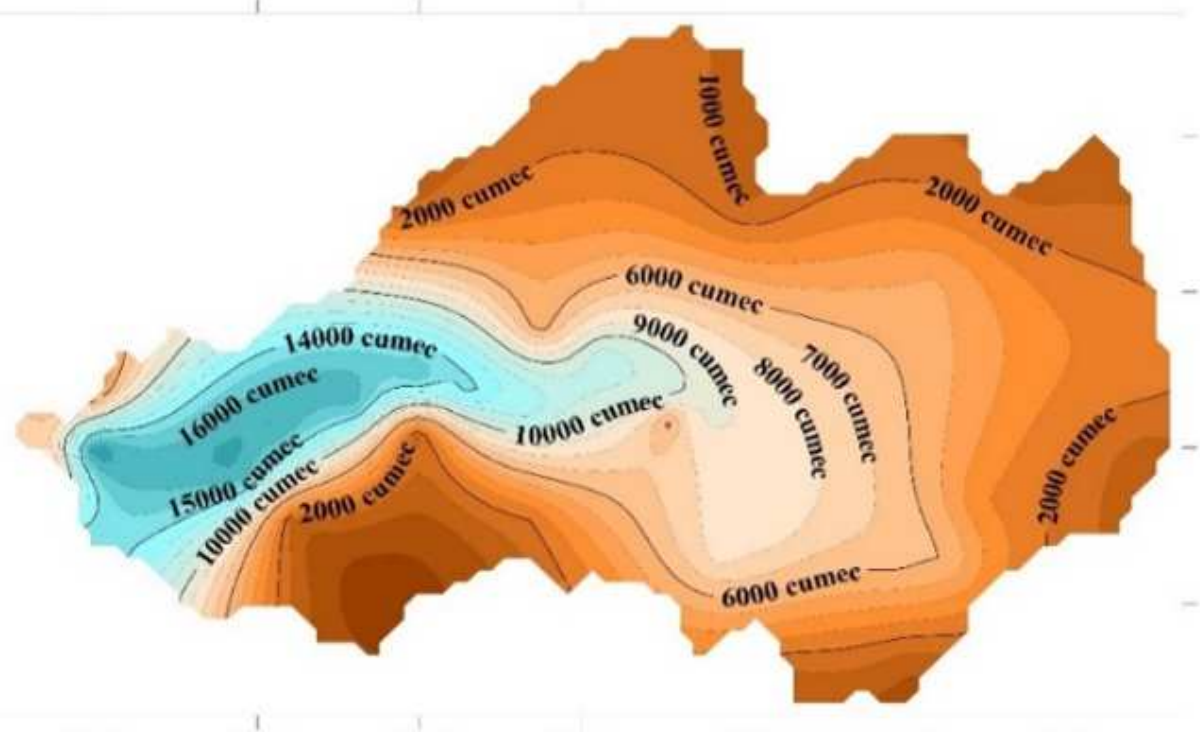

91.3
91.4
91.5

91.6

91.7

91.8

91.9

Longitude

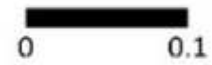

0.1

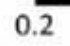

0.2

0.3

Map Seale

Figure 24 
Graphical representation of the contour map of the total flow for 2050s on Gomati River Basin (Surfer 3D Modelling). Note: The designations employed and the presentation of the material on this map do not imply the expression of any opinion whatsoever on the part of Research Square concerning the legal status of any country, territory, city or area or of its authorities, or concerning the delimitation of its frontiers or boundaries. This map has been provided by the authors.

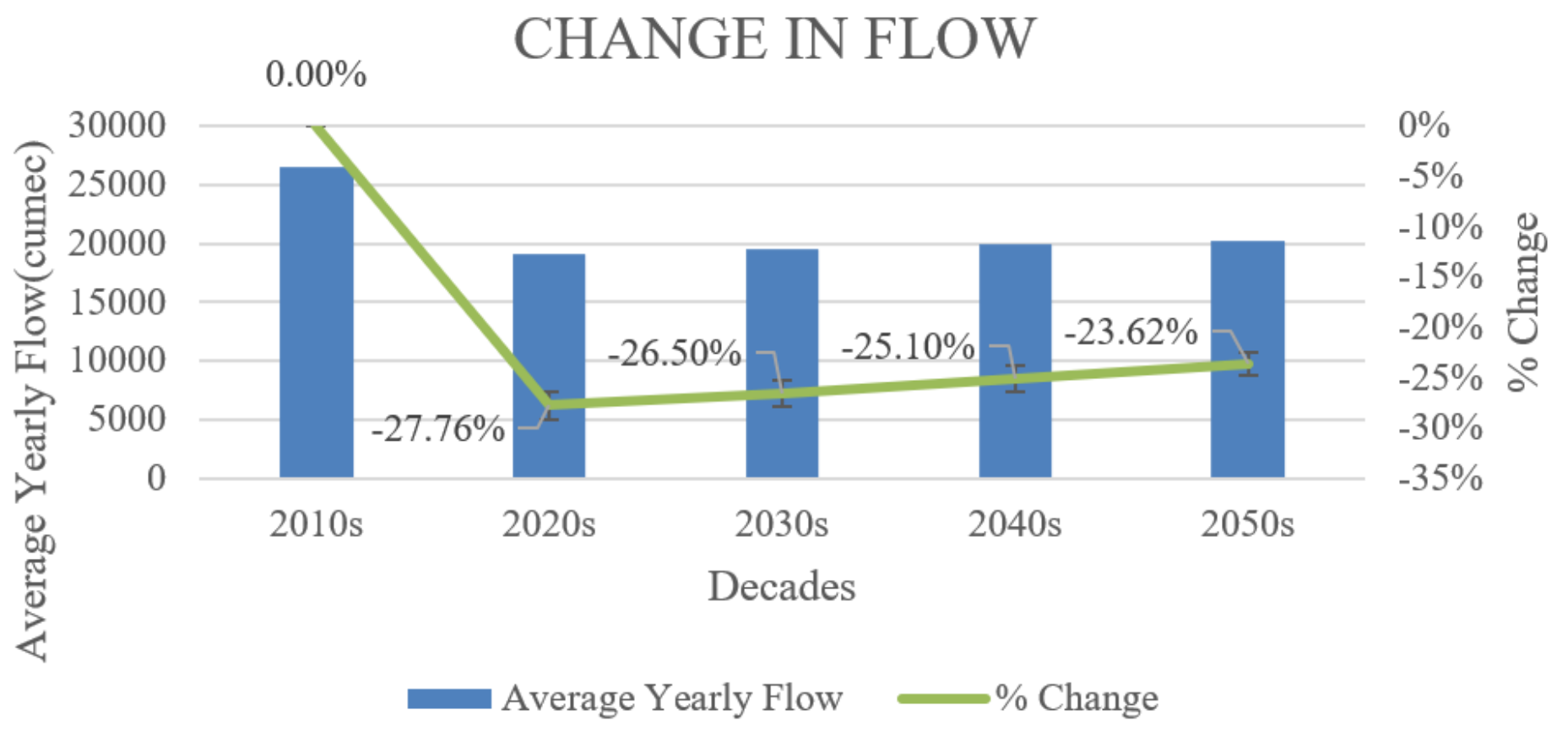

Figure 25

Graphical representation of change in flow of 2020s, 2030s, 2040s and 2050s with respect to the past decade 2010s 